\title{
Flute Vibrato during the 78-rpm Era: An Exploration of Representative Recordings of Claude Debussy's Syrinx, 1928-1953.
}

Angela Reynolds

Follow this and additional works at: https://researchrepository.wvu.edu/etd

\section{Recommended Citation}

Reynolds, Angela, "Flute Vibrato during the 78-rpm Era: An Exploration of Representative Recordings of Claude Debussy's Syrinx, 1928-1953." (2017). Graduate Theses, Dissertations, and Problem Reports. 8208.

https://researchrepository.wvu.edu/etd/8208

This Dissertation is protected by copyright and/or related rights. It has been brought to you by the The Research Repository @ WVU with permission from the rights-holder(s). You are free to use this Dissertation in any way that is permitted by the copyright and related rights legislation that applies to your use. For other uses you must obtain permission from the rights-holder(s) directly, unless additional rights are indicated by a Creative Commons license in the record and/ or on the work itself. This Dissertation has been accepted for inclusion in WVU Graduate Theses, Dissertations, and Problem Reports collection by an authorized administrator of The Research Repository @ WVU.

For more information, please contact researchrepository@mail.wvu.edu. 
Flute Vibrato during the 78-rpm Era:

An Exploration of Representative Recordings of Claude Debussy's Syrinx, 1928-1953

Angela Reynolds

Dissertation submitted

to the College of Creative Arts

at West Virginia University

in partial fulfillment of the requirements for the degree of

Doctor of Musical Arts in

Music Performance

Lynn Hileman, DMA, Chair

Travis Stimeling, PhD, Research Advisor

Nina Assimakopoulos, MM

Andrea Houde, MM

General Hambrick, MFA

School of Music

Morgantown, West Virginia

2017

Keywords: Flute, 78-rpm, Claude Debussy, Syrinx, Marcel Moyse, Martin Ruderman, JeanPierre Rampal, William Kincaid

Copyright 2017 Angela Reynolds 


\section{ABSTRACT \\ Flute Vibrato during the 78-rpm Era: An Exploration of Representative Recordings of Claude Debussy's Syrinx, 1928-1953}

\section{Angela Reynolds}

Using selected 78-rpm era recordings of Claude Debussy's Syrinx, this research will explore the development of flute vibrato in early twentieth century recordings (ca. 1928-1953). The recordings that will be used in this case study include those of prominent flutists Marcel Moyse (recordings from 1928 and 1950), Martin Ruderman (1947 - 1948), Jean Pierre-Rampal (1949), and William Kincaid (1950 and 1953). The range of recordings include those of studio quality as well as live performances on Library of Congress Music Division Concerts, each selected from Susan Nelson's The Flute on Record: The 78 Rpm Era: A Discography and further narrowed based upon availability.

Although the pedagogy of flute vibrato has now been studied more in depth, the aim of this study is to evaluate the differences in the practice of vibrato and its pedagogy in the recordings from 1928-1953. The study aims to use previous studies by Mark Katz and Martha Feldman, which trace violin vibrato practice as a result of the "phonograph effect" and castrato practice on the decline at the end of the nineteenth century respectively, as a basic model for this flute vibrato research. In addition to the recordings, the research considers the apparent influence of the French style of playing (represented by a majority of the recordings from the selected period) as well as pedagogical writings — when available — from each of the performers.

Results of the study found that vibrato trends are largely seen as a product of early recording projection needs in conjunction with the influence of the French style of flute playing, imitation (of teachers and recording artists), and modified vibrato usage of the artists due to use in the recording studio. To my knowledge, the influence of the early recording era on flute vibrato has only been explored superficially, but the aim is that this study will lay the framework for further exploration of a larger body of flute repertoire and recording artists of the early twentieth century. 


\section{Acknowledgements}

For the invaluable guidance from my research advisor and DMA committee members-Dr. Travis Stimeling, Dr. Lynn Hileman, Professor Nina Assimakopoulos, Professor Andrea Houde, and Professor General Hambrick - who dedicated a great deal of time to reading, editing, and supporting the pursuit of my degree at WVU, I cannot thank you enough.

Thank you to Beth Royall for exceptional investigative skills in helping me locate the estates of those flutists from whom I needed to seek permission. Also, to Michel Moyse and the Kincaid family (Wendy Williamson, Ms. Sparky Kincaid Allen, Anne Kincaid, Mrs. Eleanor Douglas Starke Evans, and A. Douglas Kincaid) thank you for allowing me to access the recordings of your loved ones and for adding a personal touch to my research journey.

And last, but certainly not least, to my dear husband Patrick, my parents James and Betty Collier, my siblings, my extended family, and my friends who have supported me through years of school, attended numerous performances, and never ceased to tell me that I can and will-I love you all and could not have completed this monumental journey without you. Thank you. 


\section{$\underline{\text { Table of Contents }}$}

Chapter 1: Overview of Early Recording in the 78-rpm Era

Chapter: 2: Examining Selected 78 rpm Recordings of Claude Debussy's Syrinx 9 Marcel Moyse: Recordings from 1928 and Live recording from $1950 \quad 11$

Martin Ruderman: Recording from 1947-8

Jean-Pierre Rampal: Recording from 1949

36

William Kincaid: Recording from 1950 and Live recording from 1953

Chapter 3: Conclusion - Synthesis of Findings

Appendix

60

Bibliography 


\section{Chapter 1: Overview of Early Recording in the 78-rpm Era}

According to Susan Nelson's The Flute on Record (2006), "the acknowledgement of the value of historical recordings in research and applied instrumental study is long overdue."1 There is a great deal of scholarship that addresses early recording technology, differences in equipment, and effects on general vibrato performance practice. However, it is important to consider the effect of recording technology on individual instrument practices such as flute vibrato. The topic of early recorded sound and the impact this had on a variety of performance practices is traced in Mark Katz's Capturing Sound and Martha Feldman's Castrato. Musicologist Mark Katz, for instance, has examined a variety of early violin recordings to explore the development of vibrato as a result of the "phonograph effect,"2 while Feldman's work on the recordings of castrato Alessandro Moreschi shows how early recording might be used to hear performance practices that were on the decline at the end of the nineteenth century. ${ }^{3}$ This study seeks to expand upon this research model by using recordings of Claude Debussy's oft-recorded Syrinx as a case study to understand the practice of flute vibrato in the first half of the twentieth century.

This study proposes the idea that decisions regarding the use of flute vibrato on early recordings was partially the result of a phonograph effect: needing to produce a sound that would

${ }^{1}$ Susan Nelson, The Flute on Record: The 78 Rpm Era: A Discography (Lanham, MD: Scarecrow Press, 2006), viii.

${ }^{2}$ Mark Katz, Capturing Sound: How Technology Has Changed Music (Berkeley: University of California Press, 2010), 2. Katz defines the phonograph effect as "any change in musical behavior whether, listening, performing, or composing - that has arisen in response to sound-recording technology... any observable manifestation of recording's influence."

${ }^{3}$ For more information, see Chapter 5 and 6 of Martha Feldman, The Castrato: Reflections on Natures and Kinds (Berkeley: University of California Press, 2015.) 
be heard due to limitations in technology. The pedagogical influence from the French style of playing is apparent and will be referred to throughout the document as the "French Flute School." ${ }^{\prime 4}$ Findings of this study also pose the possibility that perhaps recording artists even integrated modified vibrato use into regular performance due to conscious use during recording sessions. And, this study suggests that early recordings ultimately caused the more widespread use of vibrato through imitation.

The recordings for this case study were selected from Susan Nelson's The Flute on Record: The 78 Rpm Era: A Discography and further narrowed based upon availability. The selection occurred by seeking recorded works in the composer index which held at least five separate recordings. There were a few selections from which to choose, but the J.S. Bach Partita and Claude Debussy Syrinx stood out as they were the only two unaccompanied flute works for which five or more recordings existed. Ultimately, Syrinx was chosen over Partita, because it is a single movement work and this allowed the study to focus on the same musical content across recordings. The unaccompanied flute aspect of the selection was made in order to allow sole focus on the flutist's vibrato, not that of its interaction with other instrumentalists and other stimulus. This creates a more pure study of the vibrato aspect of the recordings and less interference with potential outcomes. The recordings selected for this study include those of

${ }^{4}$ The "French Flute School" is defined in this document with the aid of Claude Dorgeuille and Edward Blakeman, The French Flute School: 1860-1950 (London: Bingham, 1986) and Ardal Powell, The Flute (New Haven: Yale University Press, 2002), 169. Paul Taffanel was the deemed founder of this school of playing, especially as it is founded upon the premise that students aimed to imitate his playing. The "French Flute School" represents a style of playing that includes light tone (versus the "strong and steady sound" of other countries like Germany), natural musical attention to phrasing, and - specific to this study - vibrato that was intuitively musical rather than regularly vibrated. Throughout the document, "French Flute School" will refer to this general definition. In addition, Jochen Gärtner, The Vibrato, with Particular Consideration Given to the Situation of the Flutist: Historical Development, New Physiological Discoveries, and Presentation of an Integrated Method of Instruction (Regensburg: G. Bosse, 1981), 44 described French vibrato as "generally used discretely and with good taste; because of its small amplitude it was not particularly obvious." 
prominent flutists Marcel Moyse (recordings from 1928 and 1950), Martin Ruderman (1947 to 1948), Jean Pierre-Rampal (1949), and William Kincaid (1950 and 1953). ${ }^{5}$

Nelson's discography provides essential information for this study, narrowing the project to a more manageable scope. Not only does the discography include an extensive listing of recordings, it provides a brief introduction to recording technology of the late nineteenth and early twentieth centuries, as well as brief biographical information on each recording artist. This biographical information is important in the exploration of the French influence that has emerged in the collection of recording artists. The selected recordings show a wide range of influenceincluding those of Marcel Moyse of the Paris Conservatoire and Georges Barrère whose recording was not able to be acquired but who brought the French Flute School to the United States and taught William Kincaid-for this case study and will assist in determining whether this assertion of vibrato pedagogy and performance innovation is accurate. ${ }^{6}$

Although the discography made the task of selecting recordings relatively simple, the process of locating these early recordings was more challenging. Not only were early recordings often released in limited quantity, ${ }^{7}$ but it quickly became evident that the existing sources surrounding these recorded performances is limited. Unlike many later live performances, the early studio recordings were not given critical literary reviews in the same manner. Due to this gap in the literature, this study provides a detailed analysis of each recording.

\footnotetext{
${ }^{5}$ For earlier recordings of other flutists and flute repertoire, see Robert Bigio, "Christopher Steward's Early Flute Recordings" (Robert Bigio Flute Pages, Accessed January 17, 2017, http://www.robertbigio.com/recordings.htm.)

${ }^{6}$ Nancy Toff, The Flute Book: A Complete Guide for Students and Performers (New York: Oxford University Press, 1996), 112.

${ }^{7}$ Nelson, Flute on Record, vii-viii.
} 
In order to define the 78-rpm ${ }^{8}$ era for this project, this study considers Nelson's parameters given in the introduction to her discography. According to Nelson, the 78-rpm era is considered a "convenient, if inaccurate, characterization of the period covered." ${ }^{9}$ For the purposes of clarifying the dates utilized in the discography, Nelson chose from the late 1880s to 1954 as her boundaries for inclusion of recordings. This date range lends itself well to the growing popularity of flute as a more substantial instrument, but the bulk of recordings prior to 1927 were described largely as "superficial repertory." ${ }^{10}$ Coincidentally, the first recording selected for this study was recorded in 1928 by Marcel Moyse, a prominent French flutist who claims to have been the first to introduce vibrato in a woodwind. ${ }^{11}$

During the span of the 78-rpm era, recording technology consisted of two major types of recording: acoustic and electrical. Acoustic recording used a large conical horn into which the performer would play and the air pressure of the sound waves was then transcribed onto the recording medium, often a wax cylinder, with a stylus. ${ }^{12}$ This type of recording was more suited to loud instruments (including the preference for piccolo) and thus the flute was not commonly

\footnotetext{
${ }^{8}$ According to the Yale Library, The History of 78 RPM Records: A brief guide to aid in
} cataloguing, https://www.library.yale.edu/cataloging/music/historyof78rpms.htm, "78-rpm" refers to the flat discs that played at an approximate speed of 78 revolutions per minute. These were made between 1898 and the late 1950s of various materials, but shellac became the most common until vinyl was used during a shortage of shellac during World War II. Each side of a 78 held approximately 3-5 minutes per side, depending on the disc size/diameter, which would typically be either 10 or 12 inches.

${ }^{9}$ Nelson, Flute on Record, xv.

${ }^{10}$ Nelson, Flute on Record, xiii.

${ }^{11}$ Powell, The Flute, 232.

${ }^{12}$ Susan Schmidt Horning, Chasing Sound: Technology, Culture, and the Art of Studio Recording from Edison to the LP (Baltimore: John Hopkins University Press, 2013), 13; and Mark Katz, Capturing Sound, 43. 
viewed as a solo recording instrument during the period. ${ }^{13}$ In general, the acoustic era of recording spanned approximately from the 1880 s to 1925 , narrowly missing the beginning of the recordings selected for this study. However, this era is pertinent to the discussion due to the differences in technology and the affect it had on the preference for instruments other than flute. Additionally, in the early acoustic era, recordings had to be completed in one take and reproduced live due to the technology. A musician might play a piece twenty or thirty times surrounded by ten recording horns to reproduce a desired number of discs for distribution. ${ }^{14}$ Electrical recording is distinguished from acoustical recording due to the use of the electrical microphone. Generally, the electrical era ran from 1925 to 1945 -1925 being the point that major U.S. record labels began using this type of recording technology in their studios. ${ }^{15}$ However, the process of recording was still mechanical as the sound was physically inscribed onto a wax or metal disc and reproduced from the original recording also known as "masters." In other words, the musician only had to perform a selection once for distribution, although they would often make multiple takes from which to choose. ${ }^{16}$ In addition to this, recording quality improved dramatically not only in sound but also recording studio conditions, especially space concerns. ${ }^{17}$ Each of the recordings selected for this study utilize either acoustic or electrical recording technology, and this is distinguished within each recording discussion in Chapter 2.

${ }^{13}$ Powell, The Flute, 225-229.

${ }^{14}$ Horning, Chasing Sound, 13.

${ }^{15}$ Horning, Chasing Sound, 40-41; and Nelson, Flute on Record, xiv.

${ }^{16}$ Robert Philip, Early Recordings and Musical Style: Changing Tastes in Instrumental Performance, 1900-1950 (New York: Cambridge University Press, 1992), 230.

${ }^{17}$ Horning, Chasing Sound, 33. 
The 78-rpm era saw a significant development of flute recordings. According to Ardal Powell, "[f]ew instrumentalists made recordings in the early years of acoustic recording (the late 1880s to 1890)." ${ }^{18}$ The general consensus is that flutists began seriously recording in the early twentieth century and more seriously as the electrical era began. ${ }^{19}$ Powell asserts that most flutists outside of major recording cities made no recordings during the acoustic era "while the style of those who did record was markedly individual, even among French players. ${ }^{" 20}$ Surely the assertion of national styles of playing in the late nineteenth century was impacted by the continued growth of the recording industry and availability of foreign influence yielding a move toward a more universal style. This topic is reviewed as part of the synthesis of data while observing the particularly French style of flute playing influence of this study. Fortunately, the advent of electrical recording allowed the reach to a wider range of frequencies, softer dynamics, and thus allowed instrumentalists such as flutists to become serious solo artists as well. ${ }^{21}$

General woodwind vibrato has been the subject of extensive research. Robert Philip provides two books-Early Recordings and Musical Style: Changing Tastes in Instrumental Performance, 1900-1950 and Performing Music in the Age of Recording - that discuss the development of woodwind vibrato as does Nancy Toff in The Flute Book. Philip and Toff agree that, prior to the twentieth century, vibrato served as a primarily ornamental device, but thereafter received varying degrees of acceptance by prominent flutists and pedagogues. ${ }^{22} \mathrm{In}$

\footnotetext{
${ }^{18}$ Powell, The Flute (New Haven: Yale University Press, 2002), 225.

${ }^{19}$ Nelson, Flute on Record, xiv.

${ }^{20}$ Powell, The Flute (New Haven: Yale University Press, 2002), 225.

${ }^{21}$ Horning, Chasing Sound, 54; and Powell, The Flute, 231-232.

${ }^{22}$ Toff, The Flute Book, 112.
} 
fact, Philip asserts that, as "an enhancer of tone, as opposed to an ornament, [vibrato] was unknown until its development by flautists of the Paris Conservatoire" at the end of the nineteenth century. ${ }^{23}$ Powell's The Flute includes a chapter called "The Flute in the Age of Recording," which addresses different styles of playing the flute during the twentieth century. Although he discusses rhythm, phrasing, and intonation, he also includes a section on vibrato as well as a summary of Philip's research. Each of these texts contribute greatly to the foundation for this research document.

In order to establish a general working definition of current flute vibrato practice, this study has also consulted a variety of more recent sources to reach a consensus. Michel Debost's The Simple Flute claims that vibrato should not be taught unless necessary and that it should "come from the heart." ${ }^{24}$ This seems to be more in line with the late nineteenth and early twentieth century view of vibrato in which performers aimed to perform for people rather than machines. ${ }^{25}$ Powell's The Flute and Philip's Early Recordings and Musical Styles looked at early recordings and noticed the complaints that emerged from critics that vibrato in continuous use was "tiresome, irritating, and absurd" and had become widespread in violinists and singers before World War I. ${ }^{26}$ Philip also notes that flutists in the late twentieth century rarely utilized straight tone for more than a few successive notes. Most importantly, he points out that the finest players use varied vibrato with consideration of musical context. ${ }^{27}$

${ }^{23}$ Robert Philip, Early Recordings and Musical Style, 212.

${ }^{24}$ Michel Debost, The Simple Flute: An A to Z Guide (New York: Oxford University Press, 2002), 263.

${ }^{25}$ Powell, The Flute, 227.

${ }^{26}$ Powell, The Flute, 220 and 227.

${ }^{27}$ Philip, Early Recordings and Musical Style, 138-139. 
The National Flute Association's The Flutist's Handbook discusses vibrato in pedagogical terms from a variety of physical aspects (abdominal, throat, and the combination of the two) as well as the approach that vibrato cannot be taught. This section, authored by flutist Bradley Garner, also asserts that it be varied in "speed and width." ${ }^{28}$ He even provides a specific range of tempi from which a good player should be able to vary (96-128 beats per minute, using consecutive triplets. ${ }^{29}$ In summary, the late nineteenth century influence from the French Flute School indicates that vibrato was seen as an expressive but natural tool, while the current more international view of vibrato is one of a more regulated, analyzed (perhaps even over-analyzed), and taught concept. ${ }^{30}$

The case study makes up the entirety of Chapter 2 , in which the recordings are analyzed in order to establish the developments in vibrato use in the first half of the twentieth century and any impact of the French Flute School, imitation, and recording technology on flute vibrato practice. Chapter 3 synthesizes results of the case study in order to establish trends and reach a conclusion about the phonograph effect posed in this introductory chapter.

${ }^{28}$ National Flute Association (U.S.). The Flutist's Handbook: A Pedagogy Anthology (Santa Clarita, CA: The National Flute Association, Inc., 1998), 71-73.

${ }^{29}$ National Flute Association, The Flutist's Handbook, 71-73.

${ }^{30}$ Toff, The Flute Book, 111. 


\section{Chapter: 2: Examining Selected 78 rpm Recordings of Claude Debussy's Syrinx}

Claude Debussy's Syrinx was selected for the study as one of the more representative collections of recordings from the Nelson discography which provides a range of well-known flutists and recording artists, recorded dates, and happens to represent a major work from the flute literature. Additionally, Syrinx is a work for unaccompanied flute that allows the study to focus more on the topic of vibrato rather than the interaction of the vibrato within collaborative (with two more instruments) works. The selected recordings also include representation of studio and live recordings. The live recordings have been included to represent a control within the study because they fit within the selected recording dates and lend insight into the "first take" rather than subsequent takes, and perhaps variations, of the recording artists' initial ideas. In order to identify the recording types that will be utilized, microphone choice is not considered. Only the distinction between whether the recording was created by playing into a horn (acoustic) or microphone (electrical) is noted. Within this chapter, the study analyzes vibrato in each recording and considers sources that shed light on the individual recording artists' views and pedagogical approach to vibrato as supplementary material when available for the selected recording study. Due to the assertion of the great influence of the French Flute School, biographical information concerning each performer is included as available.

In order to specifically address vibrato for each recording, the research discusses the following parameters: usage versus non-usage, frequency, and amplitude (for the purpose of this study, amplitude is defined as variation in pitch.) Within each parameter, a range of variables is used. In consideration of vibrato usage throughout each recording, the range is listed where notable as: used, not used, and imperceptible. For frequency, the range is identified as slow, 
medium, and fast, along with the beats per unit of time (for example, 6 beats per eighth-note at a tempo of 85) if able to be determined. In the forthcoming figures, beats per unit of time will be listed in the heading as "subdivision." And, for amplitude, only a general range of wide to narrow is identified. However, due to the overall fast frequency of vibrato used in these recordings, it would be difficult or even impossible for a flutist to produce a truly wide amplitude of vibrato. Therefore, it should be noted that the wide-to-narrow amplitude range discussed in this study operates within an overall amplitude range that is generally considered to be narrow. At the beginning of each recording discussion, there is a table that summarizes the information regarding frequency and amplitude under the following headings: measure range, tempo, beats per unit of time (labeled with “subdivision”), pulse, average cycles per minute, and a general amplitude description.

After initial hearings of the recordings, the following areas of the piece emerged as those with the most distinct vibrato usage from each performer/recording. Each of these are included in the Appendix for reference:

- measures 1-2

- measures 6-8

- $\quad$ measures 9-11

- measures 14-17

- $\quad$ measures 26-28

- measures 31-35

This study considers vibrato usage, amplitude, and frequency in measures 1-2, 9-11, and 26-28. Only vibrato usage and amplitude are considered in measures 6-8, 14-17, and 31-35. Although 
these are not the only measures discussed for all recordings, they provide the focus from which distinct conclusions are drawn.

\section{Marcel Moyse: Recordings from 1928 and Live recording from 1950}

As one of the most influential artists of modern-day flute playing, Marcel Moyse (18891984) was one of the two major recording artists (along with René Le Roy) at the beginning of the electrical recording period. ${ }^{31}$ Moyse is also integral to this case study because he knew Debussy personally, assisted in publishing the first edition of the Syrinx score, and likely performed Syrinx privately for Debussy himself. ${ }^{32}$ His intimate knowledge of the score along with the composer's intentions provides a unique perspective to this study. Trevor Wye claims that Moyse was the "person who most closely resembled [Paul] Taffanel as far as teaching was concerned..." ${ }^{33}$ Because Taffanel was credited as the founder of the French Flute School, to which this study favours as an influence, Moyse's style of teaching and predominance in early flute recordings lends itself to being a perfect insight to the affect of this era on performance practice.

Regarding Moyse's recordings, Wye states that often the 78-rpm recordings suffered loss of quality in tone and pitch when reprocessed onto LPs. This process caused the recording to be heard at a higher frequency, resulting in faster vibrato, "not natural... of Moyse's sound,"34 Also,

${ }^{31}$ Powell, The Flute, 231.

32 Trevor Wye, Marcel Moyse: An Extraordinary Man (Cedar Falls, Iowa: Winzer Press, 1993), 67-69. Moyse refused to be listed as the editor on the score as he said that he had only "clarified some inconsistencies."

${ }^{33}$ Wye, Marcel Moyse: An Extraordinary Man, 108.

${ }^{34}$ Wye, Marcel Moyse: An Extraordinary Man, 57. 
the account from Powell's book demonstrates Moyse's claim to the introduction of vibrato. Of this account, he said:

I played for the first performance on His Master's Voice. ... We recorded, just us wind players - and it was awful! My tone had no life. What to do? Somebody suggested waving the tone. But no, I refuse. Better to go to a farm and imitate the noise of a sheep. But what I developed was the vibrato. I was the first man to introduce vibrato, not only in a flute, but in a woodwind! $!^{35}$

The quote does not define vibrato (versus waving the tone) here, but Moyse's view, in addition to that which is referenced in this study as the French Flute School's view, is generally defined as a means of expression used appropriately within musical context and is not "a systematic application to each note in the hope of rendering the entire phrase more expressive." 36 Moyse dictates exactly what appropriate musical context is by stating the following:

Among its means of expression it is certain that we have to admit the use of vibrato. A vibrato appropriate to the general sense of the phrase, intensified on certain notes or passages, supressed or discreet on others, according to the fluctuations of the said phrase, is as necessary to the interpretation as that employed judiciously by a good actor to convey a poem, narrate an anecdote or to relate a dramatic story. ${ }^{37}$

True to the actor analogy, many myths exist regarding the proper origin of Syrinx (originally titled La Flûte de Pan.) According to Moyse, via Trevor Wye, the piece was composed at the request of Gabriel Mourey as incidental music for his play Psyché. Debussy wrote the work in

${ }^{35}$ Powell, The Flute, 232. Originally from Jack Hiemenz, Marcel Moyse, Master Flutist: "I Imitate Caruso," High Fidelity/Musical America 25.1 (January 1975), 14. $2,2017$.

${ }^{36}$ Dorgeuille, The French Flute School, 101; and Email from Michel Moyse to the author, March

${ }^{37}$ Dorgeuille, The French Flute School, 101. 
order to represent "the last melody Pan plays before his death" and asked that it be played offstage. $^{38}$

\section{Recording}

\begin{tabular}{|c|c|c|c|c|c|}
\hline $\begin{array}{c}\text { Measure } \\
\text { range }\end{array}$ & Tempo & Subdivision & Pulse & $\begin{array}{c}\text { Average } \\
\text { cycles per } \\
\text { minute }\end{array}$ & $\begin{array}{c}\text { Amplitude } \\
\text { description }\end{array}$ \\
\hline $1-2$ & $80-85$ & $5-6$ & $\delta$ & 453.75 & wide \\
\hline $9-11$ & 90 & $4-5$ & $\delta$ & 405 & narrow \\
\hline $26-28$ & 104 & 6 & $\delta$ & 624 & very wide \\
\hline
\end{tabular}

Figure 1. This table demonstrates the vibrato frequency and general amplitude during the given measures on which are focused in Marcel Moyse's 1928 recording. The average cycles per minute are determined by multiplying the tempo (or average of a range of tempi) by the subdivision (or average of a range of subdivisions) of the beat.

It is important to reiterate the point that Trevor Wye made regarding the speed of the recordings as they were reprocessed making the recordings appear to have faster vibrato than what actually occurred. This should be noted, but the analysis will proceed with the given data. This recording, which occurred just a few years after the major U.S. record labels began using electrical recording technology in their studios, ${ }^{39}$ employs microphone recording equipment and provides us with the first known recording of Syrinx. This was one of Moyse's earlier recording sessions in Paris on Columbia Records, during which he spent three days in the studio. It was also during the beginning of the bulk of Moyse's solo recording career which spanned from approximately 1927 to 1938 , excluding the years surrounding World War II when he and his

${ }^{38}$ Wye, Marcel Moyse: An Extraordinary Man, 67-68; and Library of Congress Music Division concert. "Trio Moyse.” Marcel Moyse, flute, Syrinx by Claude Debussy (Live recording. March 10, 1950. Sound recording. 1967.) Moyse provided a full account written out in his personal book of philosophical quotations that describes that scene as Moyse must have seen it. This is transcribed in full on page 68 of Wye's book.

${ }^{39}$ Horning, Chasing Sound, 40-41; and Nelson, Flute on Record, xiv. 
family sought seclusion in St. Amour. ${ }^{40}$ The majority of his recordings after the war are with the Moyse Trio, and his 1950 recording fortunately provides this study with a later version of Syrinx on one of these programs.

As a musician who studied at the Paris Conservatoire just after the turn of the twentieth century, Marcel Moyse was influenced by the writings and teachings of both centuries as well as other types of musicians. Some of the most influential considerations came from vocalists and violinists of the time. Louis Spohr, a nineteenth-century violinist and composer, wrote Violinschule (1832) which discussed proper use of ornamentation such as the Bebung (tremolo) and the "changing of fingers on a single note." 41 He wrote in detail that which can be summarized into four types of vibrato that would have been, at the very least, considered at this point in time:

1. The fast type, on strongly accented notes

2. The slower type, on solemn notes in impassioned lyrical passages

3. The accelerating type on notes with crescendo

4. The decelerating type on notes with diminuendo ${ }^{42}$

Through analysis of this first recording of Syrinx, one can quickly make note of Moyse's musically appropriate vibrato use and yield insight to the earliest practice available in our study. Apart from a few brief exceptions, Moyse uses vibrato throughout this recording. The vibrato appears to present quite fast in the opening bars with 5-6 beats per eighth-note at a tempo range

${ }^{40}$ Nelson, Flute on Record, 329; and Neal Weiner, Michel Moyse, and Claude Moyse. Marcel Moyse: Grand Old Man of the Flute, DVD (West Brattleboro, Vt.: Moyse Enterprises, 2000)

${ }^{41}$ Gärtner, The Vibrato, 30.

${ }^{42}$ Louis Spohr, Violinschule (Haslinger: Vienna, 1832), 175. Quoted in Gärtner, The Vibrato, 30. 
of 80-85. As will be demonstrated by the discussion of later recordings, his vibrato is truly rather fast in frequency except in comparison with one section from the Martin Ruderman recording. The amplitude is immediately noticeable — appearing wider than that of the typical vibrato amplitude of today. Of course, Moyse would probably describe it as an expression of the natural musicality that arises from the piece and this would seem to prove true as it is quite devoted to the musical direction in the score. However, with education from the Paris Conservatoire, influence of string instruments, and more, it is likely that this information-regarding proper vibrato use - was present in some form whether in writing or even by imitation of his teachers. In the opening bars of the piece, Moyse's vibrato is relatively wide in amplitude with a frequency of 6 beats per eighth-note at a tempo range of 80-85. This remains relatively consistent through the first two measures, until the end of measure 2 where the final half-note is tapered beautifully with a decrescendo. During this decrescendo, the vibrato begins wider and narrows to nothing by the end. This provides the listener with the first instance of non-vibrato usage, and a considerable change for the ear. Also, the listener should consider that the ability to produce a beautiful taper with vibrato utilization of this type is something that requires a decent amount of practice. ${ }^{43}$ Therefore, the intention to employ this approach to vibrato had to be considered by Moyse at some point, analysed pedagogically or not. Likewise, in measure 6 the vibrato begins with a wider amplitude and narrows as the crescendo and decrescendo proceed into measure 8 . However, in measure 8, the amplitude remains narrow and continues to narrow into nothing in conjunction with the decrescendo much like measure 2 . In measure 9 , the theme appears one octave lower, and Moyse's vibrato amplitude becomes slightly narrower with a frequency of 4-5

\footnotetext{
${ }^{43}$ Gärtner, The Vibrato, 30.
} 
beats per eighth-note at a tempo average of 90 . Interestingly, when the average cycles per minute are determined (see Figure 1), it is evident that measures 9-11 actually contain a slower vibrato frequency than that of measures 1-2. Moyse still uses a wide amplitude that resembles the opening, but it is slightly narrower. This is a likely choice to be made at this point in the score to reflect the lower range and softer dynamic of piano.

Another aspect of vibrato usage that points to some type of musical planning (or pure genius on Moyse's part) is the emphasis on particular notes. In beat 3 of measure 1, Moyse emphasizes each sixteenth-note individually with vibrato, and this occurs each time the figure reappears with slight variations that will be addressed throughout this and future recordings. For instance, the sixteenth-notes on beat 3 of measure 9 are each emphasized except for the first, which appears to have no vibrato at all. However, the effect that occurs is that the emphasis is still given on this pitch despite the lack of vibrato as Moyse uses direction in his phrasing to achieve a similar effect. Another notable moment is beat 1 of measure 11, in which the sixteenthnote figure recurs but with a grace-note prior to the second sixteenth. Here, Moyse uses little to no vibrato on the first sixteenth-note and uses the grace-note to provide a launch into the more noticeable vibrato emphasis on the second sixteenth-note. This recurs in measure 12 in the similar 32nd-note figure, and is also important in relation to the vibrato frequency usage with the same figure in measure 27.

Moyse also demonstrates the use of vibrato amplitude in conjunction with other aspects of flute playing (such as tone color or variation) to create distinct differences within sections. Note here that the "standard flute vibrato" was described in France at the time as "generally used discretely and with good taste; because of its small amplitude it was not particularly obvious."

\footnotetext{
${ }^{44}$ Gärtner, The Vibrato, 39.
} 
Also, the generally narrow range of amplitude available to the flute, discussed in Chapter 1, is verified through Gärtner's writing concerning very early flute recordings in addition to personal testimonies from flutists such as Jean-Pierre Rampal who recognized vibrato's long history. ${ }^{45}$ In measures 14-17, overall the vibrato amplitude becomes narrower, while the frequency remains similar to that of measures 9-11. In fact, this frequency of vibrato dominates throughout the section between measure 9 and approximately measure 24 with slight variations that follow the musical line. For instance, in measure 15 concerning the recurring grace-note figure, the second note of each triplet is emphasized with length and no vibrato in the first two beats but with vibrato added back in the third beat. In order to lead the listener into the Cédez, (See Figure 2) the frequency of vibrato has slowed to only a triplet subdivision rather than a subdivision of 4-6, which has dominated in this recorded example. This variation also gives the impression that the amplitude has become wider in beat 3.

Figure 2. Claude Debussy, Syrinx (Paris: Société des Ėditions Jobert, 1927), measure 15. The accompanying chart lists the vibrato usage within each beat on the second note of each triplet, following the grace-notes.

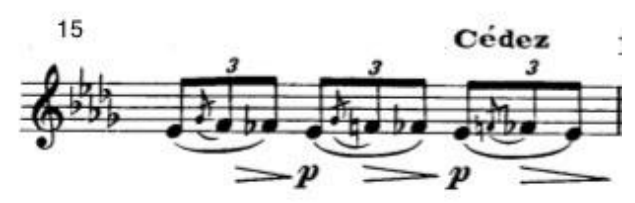

\begin{tabular}{|l|l|l|l|}
\cline { 2 - 4 } \multicolumn{1}{c|}{} & Beat 1 & Beat 2 & Beat 3 \\
\hline $\begin{array}{l}\text { Vibrato } \\
\text { Subdivision } \\
\text { on 2 } \\
\text { triplet }\end{array}$ & $\begin{array}{l}\text { No } \\
\text { vibrato of }\end{array}$ & $\begin{array}{l}\text { No } \\
\text { vibrato }\end{array}$ & $\begin{array}{l}\text { triplet } \\
\text { waver, } \\
\text { wide } \\
\text { vibrato }\end{array}$ \\
\hline
\end{tabular}

In measure 18, the eighth-notes on beats 2 and 3 are another use of the individual vibratoemphasized notes - simply moving in the opposite direction. This appears to lead to the return of

\footnotetext{
${ }^{45}$ Gärtner, The Vibrato, 39. Gärtner wrote of a personal encounter with Rampal in which he said "The French Flutists have always vibrated. A tone without vibrato does not ring."
} 
the opening vibrato frequency, but quickly moves faster. The vibrato begins to widen again and builds intensity in speed toward the return of the main thematic material. This return is significant as it presents a variation of the opening — it gradually increases past the original opening frequency of vibrato, and Moyse accelerates the frequency of the vibrato through measure 27. Here the sixteenth-note figure with the grace-note presents the fastest frequency in the entire recording: 6 beats per eighth-note at a tempo of 104 with a distinctly narrower amplitude of vibrato on the third sixteenth-note. At this point the noticeable increase in frequency, changes in amplitude, and use of the sixteenth-note vibrato emphasis come together to produce a high point in the work, fully illustrating Moyse's expertise in musicality. From here, the vibrato maintains vibrancy through fast frequency (6 beats per eighth-note at a tempo of approximately 104) and narrow amplitude through the end of measure 28. Then, Moyse returns to a slower frequency throughout the final section. Interestingly, the section from measure 29 through the end contains what seems to be the most instances of intentional non-usage of vibrato in the entire recording. Moyse manages to utilize the individual vibrato emphasis of the sixteenth-note figure throughout this section in a way that allows him to further slow the frequency and narrow the amplitude of the vibrato to the end. For instance, measure 29 contains faster rhythms that compel him to emphasize the first note of beat 1 and each sixteenth-note in beat 2 as shown in Figure 3. This vibrato treatment is repeated exactly in measure 30.

Figure 3. Claude Debussy, Syrinx, measures 29-30.

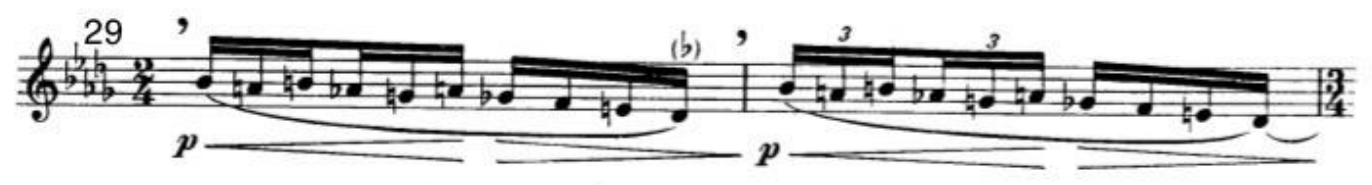


Moyse continues to demonstrate variation in this recording through some instances of non-vibrato usage in measures 31-35. However, he presents the listener with the overall effect of vibrato despite the particular moments in which no vibrato is used. In measure 31 , the notable grace-note figure reappears, this time in conjunction with the second note of a triplet. In contrast to the sixteenth-note figure, in which the second note is always emphasized with vibrato, the second and third notes of the triplet along with beat 3 of measure 31 are the most distinct and exposed moments of no vibrato usage in the entire recording. Moyse reengages vibrato with a fairly wide amplitude on beat 1 of measure 32 and leads with intensity into beat 2 where he again utilizes relatively narrow vibrato emphasis on each individual note of the triplet. The final six notes of the piece are individually emphasized with varying degrees of extremely narrow vibrato that sounds like no vibrato or, as Rampal often described this, discreet vibrato. Moyse begins the final note with no vibrato, but then begins a discreet wavering after approximately three seconds on the final note.

This analysis of the first recording yields a definitive conclusion that Moyse is deliberate with his vibrato usage, despite his view on analyzing or teaching it. It seems that he combines his vibrato choices with the directives of the score, aiding the dynamics and range appropriately at every moment. As this was early in his recording career, it is safe to assume that the musical influence of his teachers and colleagues was just as strong as that of any recording device. That being said, the quote in which Moyse claimed to have introduced woodwind vibrato to recording is not clearly dated, although it comes from an article written in 1975. Context allows it to describe one of his earliest recording sessions, likely between 1927 and 1928, but this still leaves questions. Even in The Flute, Ardal Powell recognizes that this account of invention was "not entirely 
trustworthy." 46 The main question to ask for this study is whether or not this account took place prior to the recording of Syrinx. According to the Nelson discography, the first instance of Moyse recording with other woodwinds occurred in 1927 with L'Orchestre Symphnique de Paris on Columbia Records in Paris. This would verify the timeline and support the use of vibrato throughout our case study. Whether or not its actual organized invention occurred during that exact time, Moyse established a pattern for Syrinx and other pieces to be recorded at the time with vibrato. His first recording of the piece set up a precedent for performance, whether intended or not, as this was likely the first performance many had ever heard outside of the flutist who gave its premiere, Louis Fleury. In 1928, the score had just been published, with the aid of Moyse, and the piece revived after Fleury's passing. ${ }^{47}$

Within this discussion, it is important to address the treatises written prior to the twentieth century that addressed vibrato in any fashion. The research indicates that vibrato was absolutely part of performance practice prior to Moyse, but the organization of it as the vibrato known today is not as clearly set forth. Jochen Gärtner provides a collection of writings on "vibrato" prior to this time in his book The Vibrato, with Particular Consideration Given to the Situation of the Flutist. In the book, he points to its use but mainly with an ornamental treatment by flutists such as Jacques Hotteterre (1680-1761) who addressed finger vibrato, Johann Joachim Quantz (16971773) who discussed finger vibrato but also described a "movement of the chest...not with forcefulness...rather with calmness, ${ }^{48}$ and other writers from as early as the sixteenth century,

${ }^{46}$ Powell, The Flute, 232.

${ }^{47}$ Wye, Marcel Moyse: An Extraordinary Man, 68-69.

${ }^{48}$ Johann Joachim Quantz, Versuch einer Anweisung die Flöte traversière zu spielen (Reprint, Kassel: Bärenreiter, 1953), 51. Quoted in Gärtner, The Vibrato, 22. 
such as violist Michael Praetorius (1571-1621) who attempted to teach Italian singing style ornamentation in Germany specifically noting that it should be done in "particular moderation."49 Also, Leopold Mozart (1719-1787) who introduced more formalized organization of vibrato (tremulo) through new notation that indicated speeds of vibratos of different frequencies. ${ }^{50}$ Not only is vibrato discussed in these writings, but Gärtner points out that vibrato has existed for all time as a natural part of the human voice and even in the animal kingdom. ${ }^{51}$ While there are numerous other treatises and discussions, the point is that vibrato existed prior to the twentieth century and early recording technology needs. However, the implication is that vibrato was not an organized pedagogical practice prior to these early recordings. This aspect developed as a result of the early recording era which was not kind to the flute sound (ala Moyse) and by nature does not project. Given Moyse's account of introducing vibrato, it is logical that the vibrato usage prior to the 1928 recording was obvious but discreet in the French style of playing (French Flute School.) It was then emphasized in a more methodical manner as a result of the flute sounding less than stunning in the early recording studios.

${ }^{49}$ Michael Praetorius, Syntagma Musicum Vol. III (Wolfenbüttel, 1619; Reprint Kassel, Bärenreiter, 1958), 229-230. Quoted in Gärtner, The Vibrato, 18. Gärtner also translates this into "modern terminology" as "variable in amplitude and frequency."

${ }^{50}$ Gärtner, The Vibrato, 25.

${ }^{51}$ Gärtner, The Vibrato, 15-16. 


\section{Live recording from 1950}

\begin{tabular}{|c|c|c|c|c|c|}
\hline $\begin{array}{c}\text { Measure } \\
\text { range }\end{array}$ & Tempo & Subdivision & Pulse & $\begin{array}{c}\text { Average } \\
\text { cycles per } \\
\text { minute }\end{array}$ & $\begin{array}{c}\text { Amplitude } \\
\text { description }\end{array}$ \\
\hline $1-2$ & 76 & 6 & $\delta$ & 456 & wide \\
\hline $9-11$ & $90-96$ & $5-6$ & $\delta$ & 511.5 & narrow \\
\hline $26-28$ & 108 & 6 & $\delta$ & 648 & very narrow \\
\hline
\end{tabular}

Figure 4. This table demonstrates the vibrato frequency and general amplitude during the given measures on which are focused in Marcel Moyse's 1950 recording.

This recording is of Marcel Moyse performing Syrinx as a featured solo on a live concert with the Moyse Trio at the Library of Congress. It is part of a Music Division Concert in Coolidge Auditorium on March 10, 1950. The recording was preserved on acetate disc, ten-inch reel tape (7 1/2ips, 2-track, mono.) Along with these concerts, an announcer presented introductory material about the performers and pieces, introducing Moyse as "the performer on the flute from France..." 52 This gives weight to the importance of Moyse during the time, although it should be noted that Moyse had just moved to the United States at this point and was attempting to rebuild his career in Vermont. ${ }^{53}$

In general, Moyse uses vibrato with varying frequencies throughout his 1950 recording, except for notable exceptions at measures 8 (the very end), 15, 18 (the first note), 22, and 31-35. The opening frequency of the vibrato in this recording is 6 beats per eighth-note at a tempo of approximately 76 , which averages out to roughly the same cycles per minute as the opening to the 1928 recording. Overall, Moyse uses vibrato to follow the intended dynamics and intensity of his choosing to once again aid the musical phrases. He uses vibrato almost throughout, but he

\footnotetext{
${ }^{52}$ Library of Congress Music Division concert, "Trio Moyse.”

${ }^{53}$ Weiner, Grand Old Man of the Flute.
} 
varies the frequency slightly, notably using dynamics in more variety in this recording than that of the 1928 recording. In measure 22, Moyse's distinct decision-making is evident in what was later so well-stated by flutist Roger Stevens ${ }^{54}$, that one should "never use vibration in a slurred passage where the number of vibrato pulses is equal to or less than the number of notes per second" or essentially that there was no time to place vibrato on sixteenth-note (and faster) passages without being disruptive. ${ }^{55}$ In measure 22 , the sextuplets and 32 nd-notes are clearly played without vibrato, but everything surrounding this measure is played with vibrato - and the intensity is maintained. In contrast, the final measures (31-35) contain little to no vibrato at all. As the rhythms are much slower, this must occur as a conscious decision from Moyse who always sought to approach music from the perspective of the voice. ${ }^{56}$ This "natural" approach follows the musical phrasing that Moyse strived for and so clearly portrayed at the end of the piece. This choice also points to the influence of the French Flute School's discreet and judicious vibrato usage.

Concerning Moyse's vibrato frequency in this recording, the overall frequency is faster than that of the 1928 recording. On average, the frequency varies between 6 beats per eighthnote at a tempo of 76 and 6 beats per eighth-note at a tempo of 108. Figure 1 illustrates that the 1928 recording varied between 5-6 beats per eighth-note at a tempo of 80-85 to 6 beats per eighth-note at a tempo of 104 . While the range is relatively close, the average cycles per minute

\footnotetext{
${ }^{54}$ Jan Pritchard, "Remembering Roger S. Stevens," The Flute Network, Accessed March 24, 2017, http://www.flutenet.com/stevens.htm. Roger Stevens (1921-1999) was an American flutist who wrote "The Artistic Flute - Technique and Study," was flutist and piccolo player with the Los Angeles Philharmonic Orchestra (1946-77), and received education from Eastman School of Music and the University of Michigan.

${ }^{55}$ Toff, The Flute Book, 114.

${ }^{56}$ Weiner, Grand Old Man of the Flute.
} 
make the frequency data comparison exceedingly clear. This variation of frequency and amplitude can be seen specifically in multiple places, but measure 2 is one of note. Here, in the 1950 recording, Moyse maintains the vibrato frequency and amplitude through the final B-flat of the measure and releases energetically. In contrast in the 1928 recording, this note contained a taper to no vibrato. This indicates a very thoughtful approach to the opening phrase, as this was an obvious change of musical decision-making since 1928. Also, whereas Moyse uses varied frequency of vibrato in measures 6-8 in his 1928 recording, in the live recording he uses primarily dynamics to increase the intensity of the musical phrase in measures 6-7. While the frequency has remained the same, the amplitude is the vehicle for change here. In measure 8 , the amplitude of the vibrato becomes wider on beats 1 and 2, and beat 3 is the first instance of no vibrato usage. This is quite different from the 1928 recording, as the change in the 1950 recording from vibrato to no vibrato occurs instantly on beat 3. In the 1928 recording, Moyse utilized a taper and gradual change into no vibrato at the very end of beat 3 . Perhaps the presence of a live audience should be considered as an influence on this change, and one has to admit that the faster overall frequency in this 1950 recording is noticeable. If anxiety played a part in the change of vibrato it would most certainly cause a faster frequency rather than the slower one from the 1928 recording. This begs the question of whether this resulted from time and experimentation with many prior recording sessions and performances, or if the live hall versus studio aspect had a larger effect. One cannot answer this without a personal testimony from Moyse, but evidence points to experience and decision-making as the likely culprit.

Emphasis of vibrato and variation of usage still play an important part in the musical phrasing of the 1950 recording. The grace-note figure that was so prominent in conjunction with vibrato usage in the 1928 recording is still utilized in the 1950 recording, but not with as much 
emphasis on individual surrounding notes. Likewise, the sixteenth-note figure vibrato usage on beat 3 of measure 3 is generally not as emphatic for each sixteenth-note as in the 1928 recording. Instead, the 1950 recording emphasizes the first sixteenth-note and maintains a steady vibrato through the rest of the figure. In measure 9, the one-octave lower statement of the thematic material is distinctly faster in vibrato frequency from the opening, now at 5-6 beats per eighthnote at a tempo range of $90-96$. In contrast, in the 1928 recording this restatement appears less intense due to the decreased vibrato frequency from 5-6 beats per eighth-note at a tempo range of 80-85 to 4-5 beats per eighth-note at the tempo of approximately 90 . The average cycles per minute show that the vibrato in the 1950 recording appears to have sped up at measure 9 , whereas the vibrato slowed in the 1928 recording. The frequency remains steady in the 1950 recording through measure 14 which is when the treatment of the grace-note figure once again resurfaces. Moyse treats the Cédez exactly as he did in the 1928 recording by using no vibrato on the second note of each triplet in beats 1 and 2 of measure 15 . He also uses a wide vibrato with triplet subdivision on the second note of beat 3 (Refer back to Figure 2.) It seems Moyse's musical intention is the same in this particular moment. The comparison of this moment leads to the conclusion that Moyse's musical intentions are still true to the score, but the frequency of vibrato is drastically different (4-5 beats per eighth-note at a an average tempo of 95 in the 1928 recording $=427.5$ cycles per minute, and 3-4 beats per eighth-note at an average tempo of 102 in the 1950 recording $=357$ cycles per minute) and thus lends the conclusion that the recording needs required Moyse to use vibrato more intensely in order to be heard in the manner he wished on the 1928 recording. The final measures of the piece also contribute to this as the end of the 1950 recording uses far less vibrato than that of the 1928 recording. In 1950, Moyse used no vibrato from beat 2 of measure 31 through the end, except for small wavers in the sound on the 
second note of measure 32 , beat 2 ; at the beginning of beat 2 of measure 33 ; and finally the small taper at the end of the final note. Here, Moyse actually uses no vibrato for the first 3 seconds of the final note and uses the narrowest vibrato yet within the final two seconds of the note as he tapers away to nothing (using a combination of dynamic and vibrato.) Because he did not use the taper vibrato in measures 2 and 25 (as he did in the 1928 recording), the final taper draws the listener's ear to this final section as a unique moment. Perhaps Moyse was able to more effectively utilize the acoustics of the live hall versus the smaller and less resonant studio room in which the 1928 recording was likely recorded. However, this would require an eye-witness account, of which none exists in writing. Otherwise, this is only conjecture based upon knowledge of the standard studio conditions during the time of the first recording. ${ }^{57}$

${ }^{57}$ Horning, Chasing Sound, 33. 


\section{Comparison of Moyse Recordings}

\begin{tabular}{|c|c|c|c|c|c|c|}
\hline $\begin{array}{l}\text { Measure } \\
\text { range }\end{array}$ & $\begin{array}{l}\text { Recording Artist, } \\
\text { Year }\end{array}$ & Tempo & Subdivision & Pulse & $\begin{array}{c}\text { Average } \\
\text { cycles } \\
\text { per } \\
\text { minute } \\
\end{array}$ & Amplitude \\
\hline \multirow[t]{2}{*}{$1-2$} & Marcel Moyse, 1928 & $80-85$ & $5-6$ & $\delta$ & 453.75 & wide \\
\hline & Marcel Moyse, 1950 & 76 & 6 & $\delta$ & 456 & wide \\
\hline \multirow[t]{2}{*}{ 9-11 } & Marcel Moyse, 1928 & 90 & $4-5$ & $\delta$ & 405 & $\begin{array}{c}\text { Wide, } \\
\text { slightly } \\
\text { narrower } \\
\text { than } \\
\text { opening }\end{array}$ \\
\hline & Marcel Moyse, 1950 & $90-96$ & $5-6$ & $\delta$ & 511.5 & very narrow \\
\hline \multirow[t]{2}{*}{ 14-16 } & Marcel Moyse, 1928 & 95 & $4-5$ & $\delta$ & 427.5 & narrow/none \\
\hline & Marcel Moyse, 1950 & 102 & $3-4$ & $\delta$ & 357 & wider/none \\
\hline \multirow[t]{2}{*}{$26-28$} & Marcel Moyse, 1928 & 104 & 6 & $\bar{\delta}$ & $\overline{624}$ & $\begin{array}{c}\text { very wide, } \\
\text { note: beat } 2 \\
\text { narrower }\end{array}$ \\
\hline & Marcel Moyse, 1950 & 108 & 6 & $\delta$ & 648 & very narrow \\
\hline
\end{tabular}

Figure 5. For convenience of comparison, this table demonstrates the vibrato frequency and general amplitude during the given measures on which are focused in Marcel Moyse's two recordings.

In The French Flute School, Claude Dorgeuille analyzes each of the flutists whom he believes to be representative of the French School. He discusses Moyse's playing by comparing it at the height of his career to that of his later playing while still acknowledging his superior playing ability as a mark of the discussion. Of his playing after approximately 1935, Dorgeuille writes "[t]he sound develops an almost permanent tremble" after praising his earlier playing as having an "absence of trembling." ${ }^{58}$ Clearly, Dorgeuille set forth the idea that Moyse's earlier recordings were superior in his career and that the "trembling" was not a positive attribute in representing the French School. The recordings that were analyzed in this study both illustrate Moyse's care of expression, but the change in trembling mentioned by Dorgeuille is not

\footnotetext{
${ }^{58}$ Dorgeuille, The French Flute School, 48.
} 
noticeable via these particular examples. In fact, as noted by the analysis of these recordings, it would actually seem accurate to say that Moyse is more judicious with his use of vibrato in the later recording. However, Dorgeuille's discussion does encourage exploration concerning the differences in points of Moyse's career in which he was recorded.

The study indicates that Moyse's earlier recording demonstrates a slightly slower use of vibrato, which is overall more constant. There are very few locations in the 1928 recording in which Moyse does not use vibrato. As addressed in the discussion above, these number only four or five distinct points in the relatively short piece. However, in the 1950 recording, Moyse utilizes noticeably faster vibrato frequency and generally a narrower amplitude (and more integrated into the sound) in comparison to the 1928 recording. Additionally, the points of no vibrato usage in 1950 are even more distinct, including measure $8,18,22$, and especially almost the entirety of measures 31-35. Finally, the sixteenth-note figure in which each note is individually emphasized with vibrato in the 1928 recording is a distinction that does not return in the exact same style in the 1950 recording. In 1950, the vibrato is used with a more traditional emphasis on the first of the four sixteenth-notes rather than individually vibrating each note and creating a very different musical phrase. However, the individual vibrato attention that is given to the grace-note figure introduced in measure 11, and distinctly manipulated in measures 14-16, does in fact remain in the 1950 recording — only at a slower average vibrato frequency (see Figure 5.) This grace-note figure begins to show the influence of vocal technique that was illustrated through treatment of appoggiaturas from the eighteenth through twentieth-century phrasing, which Trevor Wye describes as "a musical caress" 59

\footnotetext{
${ }^{59}$ National Flute Association, The Flutist's Handbook, 144.
} 
Many flutists of the Trevor Wye, William Bennett, and Jean-Pierre Rampal generations commonly shared personal stories of how Moyse's recordings inspired them as young flutists due to his musicality and stunning playing. His reach was far and recorded in a number of interviews. Rampal said "The first time I met Moyse was in 1936.... I was very excited...he was always a god for me...he was really the expert of the flute, the master, and the first to sing like a great singer, a great violinist or cellist." 60 That being said, it should also be noted that Moyse's influence during his short time at the Paris Conservatoire (1905-6) came from more than just flutists such as Taffanel. He also studied with violinist Lucian Capet, and thus Moyse was influenced at an early age to believe in playing not only "with strict adherence to the composers' score" but also to consider string vibrato. ${ }^{61}$ In addition to exposure to the l'Opera Comique, ${ }^{62}$ he also joined vocalist Nellie Melba on tour in 1913, a few years after leaving the Conservatoire, so the influence of natural (and rather excellent) vocal technique of the early twentieth century provided great influence on his musical decision-making. ${ }^{63}$ As both string and vocal technique at the time of the 1928 recording were already utilizing vibrato techniques, albeit of varying quality, this was a concept which Moyse undoubtedly incorporated in his performances. In fact, Toff sums up Moyse's view on vibrato here:

${ }^{60}$ Weiner, Grand Old Man of the Flute.

${ }^{61}$ McCutchan, Marcel Moyse, 64.

${ }^{62}$ Wye, Marcel Moyse: An Extraordinary Man, 56. According to Wye, Moyse used to return from l'Opera Comique and "try to express on the flute the same inspirational ideas he had just heard in the Opera House."

${ }^{63}$ Weiner, Grand Old Man of the Flute. 
...Marcel Moyse...prefer[red] to compare flute vibrato with vocal vibrato. Partly, this is because [his] concept of flute playing in general is based on the vocal model, though again flutists should use vibrato with much more restraint than singers generally do. Moyse points out several important distinctions between string and wind vibrato: while string tone is produced by the right arm, vibrato by the left, wind tone and vibrato depend on the same air column. If the dynamic is fortissimo, vibrato will be accented and intense; if pianissimo, the vibrato will be light and discreet. Also, string vibrato is subject to almost limitless variation; the wind range is far more limited. And finally, string vibrato has only a minimal influence on the pitch, whereas on the flute, pitch and vibrato are intimately related. ${ }^{64}$

This information launches this study's discovery of the influence of the French Flute School in combination with the actual recognition of the need for vibrato to enhance the sound of the flute on early recordings.

Fortunately, a set of Moyse seminars from 1975 is available on DVD, and on one of these DVDs, the invaluable masterclass covering Syrinx was located. This provided a unique source in which Moyse's teaching could be observed for this case study. The DVD, although brief, provides a perspective of the later Moyse who is a combination of both recordings in this study along with his heightened interest in pedagogy once moving to Vermont. Concerning the opening two measures, Moyse teaches the opening phrase shape by asking the student to play the outline notes (B-flat, A-flat, G-flat, B-flat, B-flat) in order to help her shape it. Afterward, he praises the phrase and makes the point "[t]hat is not Marcel Moyse's interpretation. It is music's interpretation." 65 Clearly driven by the musical phrasing that is on the page in his teaching, Moyse makes an important statement in that moment that summarizes his view on musicality which also involves vibrato. Although he does not address vibrato directly in that moment, he

${ }^{64}$ Toff, The Flute Book, 107.

${ }^{65}$ Marcel, Moyse, Blanche Honegger Moyse, Carol Wincenc, Julia Bogorad. Flute Seminars, 1975: Tape \#7: 24 Small Melodic Studies No. 9, flutist Sara Tutland; Syrinx, Debussy; flutist, Marie Herseth, DVD (West Brattleboro, Vt.: Moyse Enterprises, 1989) 
sings a very clear example that demonstrates his approach. Later, he specifically sings a phrase with and without vibrato to tell the student that the one with vibrato is superior-all without specifically saying the word "vibrato." Additionally, he gives great attention to each note, not letting the student move on until each note is at its best- "not weak." What is surely taken away from this seminar documentary is that Moyse was a pedagogue who believed in musical integrity above all, and through this short clip of him teaching Syrinx is gleaned that he did in fact advocate vibrato - at least later in his life, as demonstrated by this 1975 example. Of course, it is important to note that he believed the two to be intertwined - vibrato usage should develop from the natural musicality in a work.

It is significant that there is a set of studio and live recordings from both Marcel Moyse and William Kincaid available for comparison. Although Kincaid's recordings were spaced much closer together than those of Moyse, his recordings will lend a unique perspective to the discussion of whether time or situation (or a combination of the two) was a stronger influence on the vibrato usage in the 78-rpm era as delineated in this study. In addition to the sets of recordings, the next artist to be discussed is flutist Martin Ruderman and his 1947-8 recording.

\section{Martin Ruderman: Recording from 1947-8}

\begin{tabular}{|c|c|c|c|c|c|}
\hline $\begin{array}{c}\text { Measure } \\
\text { range }\end{array}$ & Tempo & Subdivision & Pulse & $\begin{array}{c}\text { Average } \\
\text { cycles per } \\
\text { minute }\end{array}$ & $\begin{array}{c}\text { Amplitude } \\
\text { description }\end{array}$ \\
\hline $1-2$ & 76 & 5 & $\delta$ & 380 & narrow \\
\hline $9-11$ & $112-116$ & 5 & $\delta$ & 570 & $\begin{array}{c}\text { narrow, } \\
\text { wider than } \\
\text { opening }\end{array}$ \\
\hline $26-28$ & $96-100$ & $5-6$ & $\delta$ & 539 & $\begin{array}{c}\text { wide }- \text { more } \\
\text { than opening }\end{array}$ \\
\hline
\end{tabular}

Figure 6. This table demonstrates the vibrato frequency and general amplitude during the given measures on which are focused in Martin Ruderman's 1947-8 recording. 
Although Martin Ruderman (1907-1994) is the least widely-known flutist of the selected recording artists, his recording is an important addition to the study. Biographical information is not abundant, but Ruderman was an American flutist who was deeply entrenched in the recording industry in California. He was a studio flutist with the M-G-M and $20^{\text {th }}$-Century Fox studios, performed with Artie Shaw's orchestra during the Victor recording sessions in 1940, and the Army Air Force Training Command Orchestra during NBC broadcasts of 1944-45. ${ }^{66}$ According to Leonardo DeLorenzo, he was also solo flutist of the Janssen Symphony and a solo and chamber recording artist on Delco Records. ${ }^{67}$ Note that his few recordings that are represented in Nelson's discography are largely collaborative, as in chamber or orchestral, and he was not primarily a solo recording artist during this period. Ruderman studied with Julius Furman, William Hullinger, and Anthony Linden, all of whom were considered "Hollywood flutists" or orchestral players at one time. ${ }^{68}$ Ruderman serves as yet another valuable control to this study, because he is the only recording artist available for this particular case study who was trained by flutists who did not have French teachers. His recording demonstrates the least influence of the French Flute School, not accounting for access to recordings or live performances of Syrinx from any of the other artists discussed in this case study. His recording diversifies and assists the study in more carefully deciding on the true influence on vibrato usage during the 78-rpm era.

${ }^{66}$ Nelson, Flute on Record, 406.

${ }^{67}$ Leonardo De Lorenzo, My Complete Story of the Flute: the Instrument, the Performer, the Music (Lubbock, TX: Texas Tech University Press, 1992), 330.

${ }^{68}$ De Lorenzo, My Complete Story of the Flute, 330. 
This particular recording is part of a short album which, besides Syrinx, also contains a flute, viola, and harp trio as well as a piano sonata. It is unclear when this recording of Syrinx was created, but the general consensus is that it was recorded between 1947 and 1948. The vibrato begins with a relatively narrow amplitude, and a frequency of 5 beats per eighth-note at a tempo of 76, approximately the same as Moyse's 1950 recording but still slightly slower. Immediately, due to this similarity, an intriguing point to question is whether Ruderman had access to Moyse's 1928 recording. It is entirely possible that this recording had been released in the United States by this point, and even more likely that if anyone, a studio musician in Hollywood would have access to such recordings by 1947. It is also important to note that Ruderman's recording was the first recording catalogued chronologically after Moyse's 1928 recording, following the two unpublished recordings that were not available for this case study (René Le Roy and Georges Barrère both from 1939.)

The process of comparing the recordings provides insight regarding the gap of time between 1928 and 1947-8, what if any major changes have occurred in vibrato usage, and the influence recording technology had on the two studio recordings versus the live recording. The following initial analysis focuses on comparing Ruderman's recording and Moyse's 1928 recording as the two share a few notable similarities. In measure 1, Ruderman individually emphasizes each sixteenth-note of beat 3 with vibrato as Moyse does in his 1928 recording, but this is not reflected in Ruderman's treatment of the same figure in measure 3. The taper in dynamic and vibrato at measure 2 is quite true to the 1928 Moyse recording, though not as clearly tapered to nothing by the end. Ruderman's treatment of measure 6 uses a wide amplitude that narrows through measure 7 and into measure 8 , where he suddenly utilizes wider vibrato on beat 3. Perhaps he does this to allow himself to more fully complete the taper that he employs on 
the B-flat on beat 3, narrowing the vibrato until it tapers to no vibrato at the end of the note. Measure 15 is treated exactly like Moyse's 1928 recording, with slightly wider amplitude at the end of beat 3. There is a great deal of similarity between the first half of Ruderman's recording and Moyse's 1928 recording. The general frequency of vibrato, treatment of the sixteenth-note figure in measure 1 (and recurring with variation), overall treatment of vibrato amplitude in measures 6-8, and measure 15 all point to very strong influence of Moyse's recording. Also, the need for the wider vibrato in the studio musician's hands is apparent here. By this point in time, Ruderman had been recording in studio since at least 1940, even though the Nelson discography does not reflect his output on M-G-M or $20^{\text {th }}$-Century Fox Studios.

It should be noted that Ruderman does make some very distinct choices of his own in this recording as well. In relation to his opening frequency, he uses a much faster vibrato frequency at measure 9, where Moyse (1928) slows down the average frequency to reflect the softer piano dynamic and lower register. Ruderman chooses to employ no vibrato on the grace-note figure that appears in measures 11 and 12 rather than emphasizing the note following the grace-note, and this choice is also reflected in measure 27 where most of the recordings place the largest emphasis on the E-double flat by utilizing vibrato frequency. Ruderman actually reduces his vibrato frequency to 5-6 beats per eighth-note at a tempo range of 96-100 in measure 27, following his use of 5 beats per eighth-note at a tempo of 112-116 at measure 9. This lack of emphasis on the E-double flat in measure 27 is even more of a surprise because he emphasizes both the E-double flat and F-flat in measure 22, taking time to do so in the middle of two sets of sextuplets. Even more distinct from Moyse's recording, but closer to Rampal's which follows chronologically, is Ruderman's choice of a very wide vibrato throughout the ending section (2935.) Ruderman obviously does not overly-subscribe to Roger Stevens' rule of vibrato usage 
during fast passages as he utilizes a distinctly wide vibrato throughout measures 29-30, but he does honour Moyse's individual vibrato emphasis on the sixteenth-note figure in beat 3 of both measures. In fact, he uses this as a tool to employ a ritard at the end of measure 30. Ruderman also seems to determine that the D-flat in measures 31-35 is of the utmost importance. It receives the widest vibrato usage in the recording interspersed with no vibrato usage on the remaining notes in the triplet on beat 2 of measures 31 and 32 . However his treatment of the final note is tapered from rather wide to quite narrow, but he never completely stops the vibrato usage (see Appendix.) Also on this final note, it is worth mentioning that he utilizes a very wide vibrato amplitude with a frequency of approximately 4 beats per eighth-note at a tempo of 108 until the end - a bold choice for a soft dynamic in the low range while employing only a hint of a taper! Moyse recalled that he preferred radio performances as well as the new electrical recording technology (to promote the flute) because the engineer was able to amplify the low register. ${ }^{69}$ It is possible that Ruderman was attempting to amplify the low register through his wide vibrato usage, as it most definitely makes the passage stand out to the listener. Mark Katz addresses the use of faster vibrato usage in conjunction with the projection of violin sound on recording. He asserts that vibrato usage in recording gave performers the individual identity that is automatically present as a result of the visual component in live musical performance. ${ }^{70}$ This is one element to consider along with the discussion of flute vibrato, but the evidence still points more heavily toward flute vibrato as a product of French influence, that of violin and the natural inclination of the voice to which the act of flute-playing is more closely related. ${ }^{71}$

\footnotetext{
${ }^{69}$ Powell, The Flute, 232.

${ }^{70}$ Mark Katz, Capturing Sound, 106-107.

${ }^{71}$ Toff, The Flute Book, 107.
} 
Ruderman's recording is unique from the other recording artists in a variety of ways, and this could easily be attributed to his "upbringing" away from that of the finesse of the French Flute School. That is not to diminish the west coast/United States influence, but to note that when separated from the direct French lineage and its utmost concern with specific rules of musicality, there are distinct differences. Again, it seems that Ruderman likely had the opportunity to hear Moyse's 1928 recording, or perhaps he saw a tour performance, etc. as he plays with elements of both Moyse's earlier recording style as well as elements that would be attributed to "practiced" projection in a recording studio. This recording lends a noteworthy perspective to the study as it leads the research to more fully believe that the French Flute School, over time, did spread and find its way to the furthest parts of the United States, likely via the recording industry itself. However, as any student who has studied with teachers of distinctly different backgrounds could attest, the influence of Ruderman's Hollywood-influenced teachers in addition to recordings that travelled from far-off countries would create a great deal of decision-making on the part of the student. In this recording, it seems Ruderman combined these ideas into a unique example of Syrinx and thus a perfect additional discussion topic for this study.

Jean-Pierre Rampal: Recording from 1949

\begin{tabular}{|c|c|c|c|c|c|}
\hline $\begin{array}{c}\text { Measure } \\
\text { range }\end{array}$ & Tempo & Subdivision & Pulse & $\begin{array}{c}\text { Average } \\
\text { cycles per } \\
\text { minute }\end{array}$ & $\begin{array}{c}\text { Amplitude } \\
\text { description }\end{array}$ \\
\hline $1-2$ & 84 & 5 & $\delta$ & 420 & wide \\
\hline $9-11$ & 120 & 4 & $\delta$ & 480 & narrow \\
\hline $26-28$ & $128-130$ & 4 & $\delta$ & 516 & wider \\
\hline
\end{tabular}

Figure 7. This table demonstrates the vibrato frequency and general amplitude during the given measures on which are focused in Jean-Pierre Rampal's 1949 recording. 
Jean-Pierre Rampal (1922-2000) was likely the most prolific recording artist of the flute. ${ }^{72}$ He was a student of his father Joseph Rampal, the professor of flute at the conservatory in Marseilles, and Gaston Crunelle at the Paris Conservatoire. An obvious product of the French Flute School, he spoke highly of Marcel Moyse (although he did not study with him), and contributed greatly to the popularization of the flute and its repertoire from all eras. ${ }^{73}$ Although Rampal contributed to the popularity of the flute through recordings, he gave credit to Moyse as "the first to open [the] door ...to give the opportunity to play like a solo instrument, a real solo instrument, a virtuous instrument." ${ }^{, 74}$ In an interview, Rampal admitted that he looked up to Moyse and his recordings, saying that he thought Moyse was a "god" in regard to music and the flute. ${ }^{75}$ This not only admits his admiration for the flutist, but also his influence from Moyse's recordings (imitation) and a not-so-subtle hint toward the spread of vibrato influence through those recordings.

This particular recording is one of Rampal's many, and one of an impressive 34 from the 78-rpm era that he recorded from 1946 to 1950. It was recorded with electrical microphone technology on the Boite á Musique label in France. Rampal's recording begins with a vibrato frequency of 5 beats per eighth-note at a tempo of 84. He joins Marcel Moyse's approach to the sixteenth-note figure in measure 1 by individually emphasizing each note (repeated in measures 9, 21, and 30) and then presents a stunning taper on the B-flat in measure 2. It is such a clear

\footnotetext{
${ }^{72}$ Powell, The Flute, 240.

${ }^{73}$ Nelson, Flute on Record, 392; and Weiner, Grand Old Man of the Flute.

${ }^{74}$ Weiner, Grand Old Man of the Flute.

${ }^{75}$ Weiner, Grand Old Man of the Flute.
} 
taper that the vibrato beats can almost be measured easily by ear-down from 5 to 4 to 3 to 2 and finally a single emphasized beat at the end that dissolves his taper to nothing. He resumes his opening frequency at measure 3, but measure 4-5 is where Rampal makes some changes from the other recording artists. In these measures, he uses tapers on all of the long note B-naturals and noticeably does not use vibrato on any note that is shorter than a sixteenth-note. In fact, he represents Roger Stevens' rule of vibrato usage during fast passagework excellently throughout this recording. Rampal is consistent with this lack of vibrato during faster passages and this can be seen in measures $5,12,13,20-22$, and 29-30. The idea of vibrato emphasis as well as variation of such has proven to be an important distinction between each of the recordings. Rampal's recording demonstrates notable differences from Moyse's 1928 recording, showing the listener that the same musical ideas can be represented in different ways, but that the main elements are the same - those of vibrato usage, frequency, and amplitude.

As further evidence, Rampal also makes a noticeable choice not to use vibrato in places that are different from the other artists such as the entire section between measures 14 and 19 , with the exception of five single notes. In measure 14, he vibrates on beat 2 and does not use vibrato again until measure 17 where he uses wide amplitude on beat 2 and resolves it into a narrower amplitude on beat 3. He then plays measure 18 and the entirety of beat 1 of measure 19 without vibrato before employing it again to make the leap from beat 2 into beat 3 . Here, vibrato becomes more of a staple through the rest of the piece, still taking the fast passage vibrato "rule" into account. A combination of some of Moyse and Ruderman's ideas, Rampal's final measures of Syrinx involve a wide vibrato on the long notes in measures 31-34. These are punctuated by no vibrato usage on beat 2 of measure 31 and 32, much like Moyse's 1950 recording. (Perhaps there is thoughtful influence from Rampal's choices on Moyse's 1950 recording, or the two have 
shared their musical ideas by this point in time.) The most noticeable point of vibrato variation in this section occurs in measure 33 on the B-natural, where Rampal uses a very wide amplitude and a frequency of triplet beats per eighth-note. The amplitude narrows into measure 34 and each of the remaining eighth-notes are emphasized with vibrato, once more reprising the emphasis from the sixteenth-note figure in the opening. The final note uses an extremely narrow vibrato, still utilizing the triplet beats per eighth-note from measure 33, and a taper in amplitude and dynamic to complete the recording.

Rampal's recording represents the ideals of the French Flute School through the delicate and controlled but not regular usage of vibrato and its use as an "expressive tool" rather than a constant or obtrusive occurrence. ${ }^{76}$ Despite his fairly average use of vibrato-concerning the average cycles per minute noted in Figure 7 and easily compared with other recordings in Figures 10 and 11 -this recording is one of the two that utilizes the contrast between vibrato and non-vibrato usage most evidently. This is seen in the previous discussion, which is heavily focused on the element of vibrato usage. Rampal uses the lack of vibrato to highlight his vibrato usage, making a conscious use of vibrato for ornamental or "expressive" purposes so typical of his French schooling. In direct contact with many of the French Flute School greats as well as his father who studied at the Paris Conservatoire, Rampal was heavily influenced by this style of playing. However, his tenure as a recording artist starting in the 1940s gave him a taste of microphone recording needs as well as recording developments through the time of this 1949 recording. Rampal told of his first recording contract experience in 1946 in which he recorded

${ }^{76}$ Powell, The Flute, $107 \&$ 220. On page 107, Moyse describes the natural school of vibrato as one in which the player should use a warm, singing tone, from which vibrato naturally proceeds. He is quoted just after this making light of measured vibrato by calling it "panting" and noting that this disturbs the expressive "significance of a musical phrase." 
the Mozart D-Major Quartet for Flute and Strings. He described how he had made the master recording in one flawless take, but decided to listen to it for fear of poor balance - at that time, the master could not be played back without destroying the recording. He then lamented that the recording took at least four or five more takes, never producing one that was as good as the first which had been destroyed. ${ }^{77}$ One would assume he learned a valuable lesson that day about recording takes, and this 1949 recording of Syrinx is no exception as it was completed in one beautiful take. ${ }^{78}$

It is documented by Rampal himself that he finally met Moyse in $1936^{79}$ and would have considered much of the musicality of his playing, both on records and in person by the time he made this recording. In fact, in Rampal's book Music, My Love, he writes of Moyse “...he did influence me considerably." ${ }^{80}$ Rampal was a student at the Paris Conservatoire in 1943-1944, winning his first prize on his first try in the Concours. He describes his own playing as "more open and wholehearted"81 and "very nationalistic." 82 It is likely he incorporated this freedom into his performance of Syrinx as much as his training as a French flutist. He addressed the development of the flute, its repertoire, and recording in his book and asked, "Is there any difference between a French flutist and a player from somewhere else?" He replied to this

${ }^{77}$ Jean-Pierre Rampal and Deborah Wise, Music, My Love (New York: Random House, 1989), 60.

\footnotetext{
${ }^{78}$ Nelson, Flute On Record, 392.

${ }^{79}$ Weiner, Grand Old Man of the Flute.

${ }^{80}$ Rampal, Music, My Love, 74.

${ }^{81}$ Rampal, Music, My Love, 56.

${ }^{82}$ Rampal, Music, My Love, 74.
} 
recognizing that there was once a more national style, but that due to advancements in recording and global marketing - for which he had to be grateful with respect to his huge recorded output - this was no longer distinct. Here, he also noted that he had no desire to break with the French style ${ }^{83}$, and thus his recorded output alone is a representation of the vast spread of the French Flute School over many years and countless listeners.

\section{William Kincaid: Recording from 1950 and Live recording from 1953}

William Kincaid (1895-1967) is a fitting final artist for this case study. He was an influential United States-born flutist and, much like Marcel Moyse's teacher Paul Taffanel of the French Flute School, is often viewed as the "father of the American Flute School." ${ }^{84}$ Kincaid was on faculty at the Curtis Institute of Music where he taught many of the leading United States players of the twentieth century including Julius Baker and James Pellerite, among others. As a student of French flutist Georges Barrère (1876 - 1944), this is the ideal place to introduce selected information concerning vibrato ideas of Barrère in addition to that of Kincaid. Although the recording of Barrère was not able to be located for this case study ${ }^{85}$, it is important to briefly discuss his influence on the current trends in flute playing. Undoubtedly, Barrère had an impact on Kincaid's development as a flutist, and because Barrère studied at the Paris Conservatoire

${ }^{83}$ Rampal, Music, My Love, 81.

${ }^{84}$ Demetra Baferos Fair, "Flutists' family tree: In search of the American flute school," D.M.A. diss., The Ohio State University, 2003. In ProQuest Dissertations and Theses, https://search.proquest.com/docview/305318023? accountid=2837 (accessed January 23, 2017).

${ }^{85}$ A recording of Georges Barrère performing Alfredo d'Ambrosio's Canzonetta Op. 6 with the Barrère Ensemble can be found at: Bigio, "Christopher Steward's Early Flute Recordings," http://www.robertbigio.com/recordings.htm. 
with Joseph-Henri Altès and Taffanel, this French flute lineage and its arrival in the United States is completely represented throughout the 78-rpm era in this study.

In 1905, Barrère was invited to take the position of principal flutist in the New York Symphony, leaving behind orchestral and teaching posts throughout Paris. He championed a number of chamber ensembles and new music proving the flute's worth as shown in a 1910 newspaper: "During five years in New York, Mr. Barrère has won friends for that abused instrument, the flute; has shown that its repertory includes music of the masters instead of second-class 'show pieces,' and that its players are really interpretive artists." ${ }^{86} \mathrm{He}$ is credited as one of the flutists who brought the French Flute School to the United States through his move, and specifically the practice of vibrato. This movement of vibrato to the United States was accompanied by other influential French woodwind players such as Georges Laurent (flute), Marcel Tabuteau (oboe), Georges Gillet (oboe), and later Marcel Moyse. ${ }^{87}$ Owing to his French influence, Barrère wrote of Taffanel that " $[\mathrm{h}] \mathrm{e}$ loathed cheap sentimentality, excessive expression, endless vibrato or shaking of tone, in a word, all the cheap tricks which are as undignified as they are unmusical." ${ }^{\prime 8}$ However, of Barrère's teaching, his student Francis Blaisdell said it was not "particularly verbal" and that he preferred to teach through "demonstration and imitation." 89 She recalled that he was a natural in his tone, articulation, and vibrato and "to analyse any of these techniques would have been of no interest whatsoever to

${ }^{86}$ Powell, The Flute, 228-229; and Nancy Toff, Monarch of the Flute: The Life of Georges Barrere (Oxford: Oxford University Press, 2005), 7; originally from New York Sun (1910.)

${ }^{87}$ Toff, The Flute Book, 112; and Fair, "Flutists' family tree," 25.

${ }^{88}$ Toff, Monarch of the Flute, 16. Originally quoted from: 14. Allison, "George Barrère," Flutist 2 (February 1921): 319.

${ }^{89}$ Toff, Monarch of the Flute, 245. 
him. " ${ }^{90}$ Barrère's playing was described as having "a much faster vibrato than modern listeners might expect." 91 Of course, this is likely attributed to the general influence of the French Flute School style and the refinement (in-depth analysis) of vibrato that had yet to occur.

Barrère's famous platinum flute should also be noted as this novel flute metal was carried on in Kincaid's career. Kincaid's tone was “often described as 'virile', [which] passed on a distinctively American tradition to his pupils." 92 His studies with Barrère occurred at the Institute of Musical Art (now Julliard) in New York from 1911, and it is obvious that Barrère thought highly of his playing because Kincaid served as his replacement in the New York Symphony Orchestra in his absence while touring. Kincaid also held the principal flute position with the Philadelphia Orchestra from 1921 through the 1960 season, ${ }^{93}$ an influential post in which he recorded the majority of his Nelson discography entries during the 78-rpm era. Nancy Toff asserted that William Kincaid was "the pioneer in developing a slower vibrato" and that he also sought a more intense vibrato. ${ }^{94}$ A quote from a New York Philharmonic flutist Paige Brooke described Kincaid's contribution to flute vibrato as making it more like string vibrato: "smoother and more controlled, variable frequency vibrato depending on what intensity one wants, and making it an integral part of flute playing." 95 The research will explore this in relation to the previous recordings discussed to determine its merit in this case study.

\footnotetext{
${ }^{90}$ Toff, Monarch of the Flute, 245.

${ }^{91}$ Toff, Monarch of the Flute, 289.

${ }^{92}$ Powell, The Flute, 241.

${ }^{93}$ Nelson, Flute On Record, 220.

${ }^{94}$ Toff, The Flute Book, 113.

${ }^{95}$ Eleanor Lawrence, "Interview with Paige Brook," National Flute Association Newsletter 3, no. 1 (1977), 3; quoted in Toff, The Flute Book, 113.
} 
Toff argues that Kincaid was careful, but devoted with his vibrato usage and that in the (American) generations following him, "little has changed in terms of basic tonal ideals, with the exception that vibrato commands a good deal of pedagogical attention." ${ }^{96}$ While this case study does not extend beyond the reach of William Kincaid, it would be quite interesting to explore this statement in regard to the extended "American Flute School" (as deemed by Toff) and its further study of vibrato. It is also worth noting this quote in regard to Kincaid's impact because it asserts that he opened the door to true pedagogy surrounding vibrato and thus confirms his status as the father of the "American School"- at least in respect to vibrato.

His writings, although few in print, speak clearly to his view of vibrato. According to Kincaid's book, The Advanced Flutist: A Guide to Multiple Tonguing, Vibrato, and Sensitive Fingerings, on which he collaborated with student Claire Polin, he views vibrato as a vibrating effect that enhances the tone and "give[s] it life." 97 He goes on to describe how this is done, internally for wind players and singers, and notes that most players likely have already produced vibrato without awareness of it. He generously walks the reader through his method of vibrato, and instructs to use it in slow, expressive passages rather than during fast passages where a "straightforward tone" would be more appropriate. ${ }^{98}$ This, in particular, is significant to trace through Kincaid's recordings to determine if vibrato is utilized in this way - and whether it is similar or greatly altered between the live and studio recordings.

${ }^{96}$ Toff, The Flute Book, 102.

${ }^{97}$ William Kincaid and Claire C. J. Polin. The Advanced Flutist: A Guide to Multiple Tonguing, Vibrato and Sensitive Fingering (Bryn Mawr: Elkan-Vogel, 1975), 60.

${ }^{98}$ Kincaid, Advanced Flutist, 60. This section on vibrato also includes musical excerpts from the F.A. Hoffmeister Concerto in $D$ with which the flutist can practice utilizing the vibrato in the way Kincaid describes. Also, on page 79-81, he provides two more excerpts for the flutist to practice this appropriate vibrato usage. 
1950 Recording

\begin{tabular}{|c|c|c|c|c|c|}
\hline $\begin{array}{c}\text { Measure } \\
\text { range }\end{array}$ & Tempo & Subdivision & Pulse & $\begin{array}{c}\text { Average } \\
\text { cycles per } \\
\text { minute }\end{array}$ & $\begin{array}{c}\text { Amplitude } \\
\text { description }\end{array}$ \\
\hline $1-2$ & 72 & 6 & $\delta$ & 432 & medium \\
\hline $9-11$ & 104 & $4-5$ & $\delta$ & 468 & very wide \\
\hline $26-28$ & 80 & $5-6$ & $\delta$ & 440 & $\begin{array}{c}\text { wide, then } \\
\text { narrow }\end{array}$ \\
\hline
\end{tabular}

Figure 8. This table demonstrates the vibrato frequency and general amplitude during the given measures on which are focused in William Kincaid's 1950 recording.

Kincaid's 1950 recording was recorded on Columbia Records (likely in Philadelphia) on May 16, and picks up in the timeline just after Moyse's recording with the Moyse Trio in March of the same year. Definitively recorded by microphone at this point in time, Kincaid also recorded three other substantial works on the same day, half of which were not published on 78rpm but were later released on LP. However, it is worth noting that this set of recordings was made on both disc and tape. ${ }^{99}$

In his recordings, Toff's assertion that Kincaid is the pioneer of slower vibrato is fully proven. This 1950 recording demonstrates some of the slowest use of vibrato in the case study, and reveals that the pedagogical thought had been placed on vibrato by this point-at least in the United States. The data in Figures 10 and 11 definitively show that Kincaid's average cycles per minute are slower overall in this and his later 1953 recording. In 1950, Kincaid's opening phrase begins with a medium to wide amplitude vibrato with a frequency of 6 beats per eighth-note at a tempo of 72. This is distinctly different from all of the other recording artists in this study demonstrating the slowest opening tempo, but with the beats per eighth-note occurring at the same rate as that of Moyse in 1950. Overall, the opening vibrato lends a more cautious feeling to

\footnotetext{
${ }^{99}$ Nelson, Flute On Record, 226.
} 
the first musical phrase, and it allows more variety in the vibrato throughout the performance. Kincaid makes use of this variety in a manner similar to that of Rampal's recording with a great contrast between vibrato and no vibrato usage. This is reminiscent of the French Flute School training he received from Barrère combined with his careful planning of each move in conjunction with the natural expressive nature of the piece. To further demonstrate this combination of considerations, in measure 2, Kincaid utilizes his wide and relatively slow vibrato in what seems to be a very carefully planned taper on the final B-flat. Like Rampal's recording, the taper is evident in both dynamic and vibrato frequency, which is easily measured from 6 to 5 to 4 to 3 pulses and finally to no vibrato. The distinctly measured vibrato reprises itself quickly in Rampal's recording at measure 8, but in this Kincaid recording there is a more drastic use of vibrato in that location. Here, he has built a crescendo and decrescendo into measures 6-7 not only in dynamic but with very precise attention to the vibrato frequency and amplitude. He begins with a narrow amplitude and the opening frequency, then increases amplitude width and frequency along with the dynamics in measures 6-7. He then returns to a slower and narrower vibrato just before measure 8 . By measure 8 , Kincaid has slowed the vibrato frequency before abandoning it altogether on the final B-flat. This moment is unlike any other recording studied thus far as all others have tapered or vibrated to the end of this particular phrase. In the next measure, the amplitude and usage become more noticeable than the frequency (which is rather moderate with 4-5 beats per eighth-note at a tempo of 104.) By employing a wide amplitude of vibrato, this section (measures 9 to 25) presents the most unique performance of Syrinx in this case study. With very little vibrato usage throughout this section, it hearkens back to the discussion of vibrato as an ornamental tool, such as the nineteenth-century flutist Charles Nicholson and his contemporaries utilized. Nicholson, a virtuoso soloist, referred to this 
as a "vibration" defined as "an embellishment that should resemble the beats or pulsations of a bell or glass; it should be slow at first, increasing in rapidity as the sound diminished." ${ }^{100}$ In this way, Kincaid reprises this extremely thoughtful application of "vibration" in this recording. He follows Roger Stevens' rule of vibrato usage (rather lack thereof) in fast passagework and generally does not even use vibrato on the sixteenth-notes in this passage. Most notably, the much-discussed grace-note figure that occurs in measure 11 is presented in this recording without any vibrato whatsoever. In other recordings, the artists have used vibrato to emphasize the second sixteenth-note, deemphasize the note, and even to simply play straight through the entire figure with a constant shimmering vibrato. However, Kincaid presents yet another idea here that, in its simplicity, embraces the rules of the past and breaks with them at the same time. The vibrato choice he makes in that moment utilizes Stevens' rule for non-usage of vibrato in fast passagework, but the choice to do this had to be analyzed and planned because not one of the prior recording artists presents the same musical phrasing. He treats this moment as a gesture in progress to measure 13 rather than something at which to arrive in and of itself. It is a significant difference and examines whether this was a decision perhaps made based upon the studio setting of the recording or if the confluence of his French and American influence simply stated this musical phrase with a unique new perspective. Kincaid uses the least vibrato of all the recording artists, except Rampal, throughout the remainder of the piece. In fact, the remaining section is one that would lead the listener to question whether Kincaid may have heard Rampal's recording and imitated. Although this cannot be verified, the similarities between the two recordings is something of which to make note. In measures 14 through 25 , Kincaid only uses vibrato to

${ }^{100}$ Toff, The Flute Book, 110. 
emphasize certain notes, and the number of notes decorated with vibrato increases until measure 19 where the vibrato becomes distinctly audible with a very wide amplitude. The following measures contain little vibrato usage except on longer notes until the fermata at measure 24 , in which Kincaid employs his vibrato frequency crescendo with a distinctly wide amplitude. The return of the thematic material in measures 26-28 reveals the slowest frequency from all of the artists in this study (at this particular point in the score) with 5-6 beats per eighth-note at an average tempo of 80 . Here, Kincaid uses a gradual increase of the frequency from the first note of measure 26 through the beginning of measure 27 . While most of the other recording artists use measure 27 as a chance to vibrate wildly and/or emphasize the E-double flat within beat 2, Kincaid chooses to leave this particular note without vibrato and leans on it with air emphasis instead. The key word here is "chooses" because this is a distinct choice that Kincaid made concerning vibrato in a moment in which all other recordings in this study chose not to approach it in this way. Choice comes from thoughtful approach which results from a pedagogue who by this point in his career had been teaching students how and when to vibrate for many years.

Furthermore, Kincaid continues to use minimal vibrato adhering to Stevens' vibrato usage rule until measure 31 where the vibrato is utilized once again as a crescendo and decrescendo tool throughout this section and through the final measure. He does this with slight variation of frequency, but more notably through amplitude. On beat 3 of measure 32, the long note is a perfect example of the decrescendo that Kincaid creates with amplitude and dynamic combination - both of which diminish (wide to narrow and louder to softer respectively.) Kincaid uses a narrow amplitude on the final B-natural in measure 33 and varies this by widening toward the apex of the note on the downbeat of measure 34 then narrowing again as he completes this B-natural. The remaining five notes are played without vibrato, except for a slight 
"swell" in the middle of the final note that involves the most delicate of beating with an extremely narrow amplitude range in place of a dynamic swell.

In addition to the slower average frequency, overall Kincaid's amplitude is wide, but narrower than many of the other recording artists throughout this recording. This is likely in conjunction with his marked attempts to play and teach students to use an open sound, which would require more openness in the throat. ${ }^{101}$ Also of note here is Kincaid's description of vibrato in relation to a full and beautiful tone: "To Alice in Wonderland there was a Cheshire cat which grinned. Suddenly the cat disappeared and only the grin was left. Equation - grin, no cat $=$ vibrato, no tone." ${ }^{102}$ Toff goes on to explain this humorous but accurate analogy of vibrato as an ornament: "while present, an integral part of the tone, but the tone must be capable of standing on its own without any vibrato enhancement."103

In summary of this recording, Kincaid has combined the natural or instinctual expressive vibrato approach of the French Flute School with the curiosity Moyse associated with United States flutists who seek to ask why and how. Moyse is quoted as making light of the desire to analyze vibrato rather than simply make music. He likens it to overanalyzing kissing! ${ }^{104}$ As intriguing as the metaphor is, the pedagogical approach became more appealing to the United States flutists who desired to figure out how to imitate these brilliant artists from their recordings, masterclasses, and live performances. Toff stated that not much has changed in the

${ }^{101}$ John C Krell, Kincaidiana: A Flute Player's Notebook (Santa Clarita, CA: The National Flute Association, Inc., 1997), 4.

${ }^{102}$ Frederick B Chapman, Flute Technique (New York: Oxford University Press, 1973), 100; Quoted in Toff, The Flute Book, 114.

${ }^{103}$ Toff, The Flute Book, 114.

${ }^{104}$ National Flute Association, The Flutist's Handbook, 144-145. 
general tonal ideas since Kincaid except that "vibrato [now] commands a good deal of pedagogical attention." ${ }^{105}$ While this could be up for quite a debate, the consensus of studies here indicate she is accurate in asserting that Kincaid made this change. Vibrato has remained slower overall than the French recording artists presented in this study, and the establishment of a true vibrato pedagogy and performance practice has occurred in much greater detail since Kincaid's influential career.

\section{Live recording from 1953}

\begin{tabular}{|c|c|c|c|c|c|}
\hline $\begin{array}{c}\text { Measure } \\
\text { range }\end{array}$ & Tempo & Subdivision & Pulse & $\begin{array}{c}\text { Average } \\
\text { cycles per } \\
\text { minute }\end{array}$ & $\begin{array}{c}\text { Amplitude } \\
\text { description }\end{array}$ \\
\hline $1-2$ & 76 & 5 & $\delta$ & 380 & wide \\
\hline $9-11$ & 126 & $3-4$ & $\delta$ & 441 & wide \\
\hline $26-28$ & 100 & 5 & $\delta$ & 500 & $\begin{array}{c}\text { narrow, then } \\
\text { wide (in 27) }\end{array}$ \\
\hline
\end{tabular}

Figure 9. This table demonstrates the vibrato frequency and general amplitude during the given measures on which are focused in William Kincaid's 1950 recording.

William Kincaid performed Syrinx on a Philadelphia Woodwind Quintet concert as part of another live recording from the Library of Congress Music Division Concerts in Coolidge Auditorium on February 13, 1953. This recording was preserved on ten-inch reel (71/2 ips, 2track, mono.) It was broadcast in New York on WNYC, but no Washington, D.C. broadcast can be found ${ }^{106}$ On the live recording of Kincaid's performance in 1953, the announcer stated that Syrinx should be performed "in complete darkness to allow its beauty to be undisturbed by any

\footnotetext{
105 Toff, The Flute Book, 102.

${ }^{106}$ Nelson, Flute On Record, 227.
} 
visual distraction." ${ }^{107}$ Whether Kincaid or the announcer provided this note is unclear, and one would highly doubt that Kincaid had the lights turned off in Coolidge Auditorium for this performance. The recording does verify that he safely walked onto the stage with full audience applause. It should be noted that Louis Fleury, the flutist who premiered Syrinx and had sole access to the work until his death in 1926, often performed the work in the concert setting offstage, as also intended by Debussy. ${ }^{108}$ The picture this setting paints for the audience is one of simplicity due to the dark and/or off-stage staging intention. Perhaps, Kincaid also aimed to utilize his vibrato in a way that reflected this.

This recording uses a slower average frequency of 5 beats per eighth-note at a tempo of 76 in comparison with Kincaid's 1950 recording which began with 6 beats per eighth-note at a tempo of 72. Average cycles per minute are shown in Figures 8 and 9, and the differences, although slight, are noticeable. The vibrato is immediately presented with a wider amplitude, providing a more present sound and a less cautious approach than the opening of the 1950 recording. This 1953 recording further proves Nancy Toff's statement that Kincaid pioneered slower vibrato, which was already so perfectly proven through the vibrato usage in the 1950 recording. This live recording also still makes use of the "selectively expressive" vibrato attributed to Kincaid. ${ }^{109}$ In fact, Kincaid remained remarkably true to his overall view of the phrasing and vibrato usage from the 1950 recording, with slight alterations. After a comparison

${ }^{107}$ Library of Congress Music Division concert, "Philadelphia Woodwind Quintet," William Kincaid, flute, Syrinx by Claude Debussy (Live recording. February 13, 1953.)

${ }^{108}$ Wye, Marcel Moyse: An Extraordinary Man, 68.

${ }^{109}$ Toff, The Flute Book, 114. 
of analysed scores, this discussion is served best by pointing out the brief list of differences rather than similarities between the two recordings.

As noted before, the slightly slower vibrato usage is the first noticeable difference between the two Kincaid recordings. It is worth reiterating that the 1953 recording is from a live setting in which he performed a concert with a woodwind quintet, and thus had to adjust his vibrato usage for blending purposes. This influence, especially that of a clarinetist who might not choose to use much or any vibrato at all, ${ }^{110}$ could alter Kincaid's perception of his own usage and encourage him to vibrate differently when moving from the ensemble setting to that of a soloist. However, it is logical to think that a pedagogue like Kincaid was well aware of this change and would be mindful as such. As the two recordings are merely three years apart, perhaps Kincaid had given even more in-depth thought to the pedagogy of vibrato usage at this point.

The next point in which Kincaid makes a distinct change is in measures 6-8, where he approaches the phrasing of the long notes with dynamic and vibrato amplitude changes in both recordings. In the 1953 recording, the amplitude varies from quite narrow to extremely wide and back to narrow, ending with no vibrato at all on the B-flat in measure 8 . This is reflected in the dynamic changes and demonstrates Kincaid's ability to be extremely flexible with his vibrato range - thus the French style coming through. After this moment, the only true difference between Kincaid's recordings are slight variations in frequency until measure 26 where the individually emphasized sixteenth-note pattern, so prominent from Moyse's 1928 recording, is now present here in Kincaid's 1953 recording. On Kincaid's 1950 recording, beat 3 of measure 26 was a moment in which he distinctly chose not to use vibrato with only a slight phrasing lean

${ }^{110}$ Robert Philip, Performing Music in the Age of Recording (New Haven: Yale University Press, 2004), 95; and Toff, The Flute Book, 113. 
on the first sixteenth-note. Perhaps this also informed his treatment of the grace-note figure in the following measure in each recording. In 1953, the use of individual vibrato emphasis in measure 26 is paired with intense vibrato usage in measure 27 where the vibrato frequency (5-6 beats per eighth-note at a tempo of 100) is paired with very wide amplitude on the E-double flat that follows the grace note. In contrast, the 1950 recording utilizes no vibrato on this particular note following the usage of no vibrato on the sixteenth-notes in measure 26 (see Appendix.)

Following measures 26-28, the final measures of the piece contain the only other minor difference between the two recordings. Measures 31-34 demonstrate slight differences in frequency, but nothing truly notable in concrete numbers due to the flexible nature of the final five measures. Even the vibrato usage in measures 31-34 is remarkably similar in both the 1950 and 1953 recordings. However, amplitude stands out as the most notable difference between the two recordings, especially in measure 35 . The final note of the piece, in the 1953 recording, is more distinct in that the amplitude is wider during the vibrato swell than that which is utilized in the 1950 recording. That being said, the approach to the swell is still very similar and the amplitude differences only point to slight variation between Kincaid's recordings. However, the question of recording's influence on minute musical choices such as this is raised, especially because the final note is more distinctly wider in the live 1953 recording. Because of this, one is led to believe that Kincaid chose a narrower vibrato in the studio recording as a statement of musical choice - obviously influenced by the more discreet vibrato approach of the French Flute School. Also, this moment in the studio recording likely translates to presenting the soft dynamic with less presence, utilizing narrow to no vibrato rather than the wider vibrato Katz associates with a more distinct performer presence. 
As evidenced through this study, Nancy Toff rightfully describes William Kincaid as the "master of selectively expressive vibrato" $" 111$ He takes great care to use vibrato as a tool for expression in a way that highlights the musical phrasing of the piece in both recordings. Specifically, Kincaid's use of vibrato frequency and amplitude is able to create more effective dynamics or even act as a dynamic by themselves - all affectively focusing on the musical expression. When Moyse arrived in the United States, he commented strongly about the usage of vibrato in the French style, saying "vibrato is used so excessively [in France] that all music is distorted by its constant waver." 112 With this in mind, it is likely that the pedagogical movement in the United States around this time was aimed at making vibrato more fluid and a part of the flute sound rather than something to focus on instead of the sound.

111 Toff, The Flute Book, 114.

112 "Marcel Moyse Profiled," Woodwind Magazine 2, no. 5 (1950), 12; Quoted in Toff, The Flute Book, 112. 
Chapter 3: Conclusion - Synthesis of Findings

\begin{tabular}{|c|c|c|c|c|c|c|}
\hline $\begin{array}{l}\text { Measure } \\
\text { range }\end{array}$ & $\begin{array}{c}\text { Recording Artist, } \\
\text { Year }\end{array}$ & Tempo & Subdivision & Pulse & $\begin{array}{l}\text { Average } \\
\text { cycles } \\
\text { per } \\
\text { minute }\end{array}$ & Amplitude \\
\hline \multirow[t]{6}{*}{$1-2$} & Marcel Moyse, 1928 & $80-85$ & $5-6$ & $\delta$ & 453.75 & wide \\
\hline & Marcel Moyse, 1950 & 76 & 6 & $\delta$ & 456 & wide \\
\hline & $\begin{array}{c}\text { Martin Ruderman, } \\
1947-8\end{array}$ & 76 & 5 & S & 380 & narrow \\
\hline & $\begin{array}{c}\text { Jean-Pierre Rampal, } \\
1949\end{array}$ & 84 & 5 & $\delta$ & 420 & wide \\
\hline & William Kincaid, 1950 & 72 & 6 & $\delta$ & 432 & medium \\
\hline & William Kincaid, 1953 & 76 & 5 & $\delta$ & 380 & wide \\
\hline \multirow[t]{6}{*}{$9-11$} & Marcel Moyse, 1928 & 90 & $4-5$ & $\delta$ & 405 & $\begin{array}{c}\text { Wide, } \\
\text { slightly } \\
\text { narrower } \\
\text { than } \\
\text { opening }\end{array}$ \\
\hline & Marcel Moyse, 1950 & $90-96$ & $5-6$ & $\delta$ & 511.5 & very narrow \\
\hline & $\begin{array}{c}\text { Martin Ruderman, } \\
1947-8\end{array}$ & $112-116$ & 5 & S & 570 & $\begin{array}{l}\text { narrow - } \\
\text { wider than } \\
\text { opening }\end{array}$ \\
\hline & $\begin{array}{c}\text { Jean-Pierre Rampal, } \\
1949\end{array}$ & 120 & 4 & $\delta$ & 480 & narrow \\
\hline & William Kincaid, 1950 & 104 & $4-5$ & $\delta$ & 468 & very wide \\
\hline & William Kincaid, 1953 & 126 & $3-4$ & $\delta$ & 441 & wide \\
\hline \multirow[t]{6}{*}{$26-28$} & Marcel Moyse, 1928 & 104 & 6 & $\delta$ & 624 & very wide \\
\hline & Marcel Moyse, 1950 & 108 & 6 & $\delta$ & 648 & very narrow \\
\hline & $\begin{array}{c}\text { Martin Ruderman, } \\
1947-8\end{array}$ & $96-100$ & $5-6$ & $\delta$ & 539 & $\begin{array}{l}\text { wider than } \\
\text { beginning }\end{array}$ \\
\hline & $\begin{array}{c}\text { Jean-Pierre Rampal, } \\
1949\end{array}$ & $128-130$ & 4 & $\delta$ & 516 & wider \\
\hline & William Kincaid, 1950 & 80 & $5-6$ & $\delta$ & 440 & $\begin{array}{l}\text { wide, then } \\
\text { narrow }\end{array}$ \\
\hline & William Kincaid, 1953 & 100 & 5 & $\delta$ & 500 & $\begin{array}{l}\text { Narrow, } \\
\text { then wide } \\
\text { (in 27) }\end{array}$ \\
\hline
\end{tabular}

Figure 10. All results from each recording are included in this chart for ease of comparison. 


\begin{tabular}{|l|l|l|l|c|}
\hline Recording & \multicolumn{4}{|c|}{ Average cycles per minute } \\
\hline Artist, Year & mm. 1-2 & mm. 9-11 & mm. 26-28 & Average of entire piece \\
\hline Marcel Moyse, 1928 & 453.75 & 405 & 624 & 494.25 \\
\hline Marcel Moyse, 1950 & 456 & 511.5 & 648 & 538.5 \\
\hline Martin Ruderman, 1947-8 & 380 & 570 & 539 & 496 \\
\hline Jean-Pierre Rampal, 1949 & 420 & 480 & 516 & 472 \\
\hline William Kincaid, 1950 & 432 & 468 & 440 & 446 \\
\hline William Kincaid, 1953 & 380 & 441 & 500 & 440 \\
\hline
\end{tabular}

Figure 11. Here, the average cycles per minute of vibrato is presented along with an additional column which includes the average of the cycles per minute for the entire piece for each recording. This conclusion is reached by averaging the cycles per minute of measures 1-2, 9-11, and 26-28.

The analysis of studio and live recordings of Claude Debussy's Syrinx from Marcel Moyse, Martin Ruderman, Jean-Pierre Rampal, and William Kincaid alongside biographical information, pedagogical writings, and declarations against the organized study of vibrato by famous pedagogues reveals the influence of imitation, the pedagogy of the French Flute School (lineage), and projection needs in early recording on today's vibrato performance practice. Overall — as evidenced especially by the study of Kincaid in addition to modern-day sourcesvibrato practice is now slower as well as studied and taught more in depth than in the early twentieth century. This new, more universal language of vibrato has resulted from years of recordings, teachers, and in-depth study.

Generally, Marcel Moyse's recordings demonstrate a faster vibrato frequency than that of the later recordings in this study. Also, his vibrato is more constantly used in the 1928 recording, which indicates the necessity for faster and consistent vibrato in order for the flute to be present on the recording. This assertion is supported by the writings of French flutists as well as flutists from countries such as Germany and Britain who had a more conservative view of vibrato at the 
beginning of the twentieth century. ${ }^{113}$ Together, Moyse's recordings act as a reference point from which comparisons are made in this study. Not only was he one of the first major flute recording artists, but he also represented the ideals of the French Flute School vibrato (so recently developed as a staple in playing at the end of the nineteenth century ${ }^{114}$ ) and thus the launching point from which the current vibrato practice was formed. Coincidentally, or not, Moyse presents the first known recording of Syrinx and thus established the baseline for this study.

The analysis of the two sets of recordings from Moyse and Kincaid provide a significant grounding to this study. In order to determine whether live performance was affected by the implementation of specific vibrato usage in recording, these sets of recordings were analyzed in comparison as well. While Moyse was a direct product of the French style vibrato, his recordings indicated that his vibrato actually sped up from 1928 to 1950 . This is perhaps due to the "tremble" mentioned, but it suggests that his continued recording career played a unique role in his personal vibrato development for live performance, as well. In a comparison of Kincaid's two recordings, one quickly notices that his vibrato slows down overall in the later live recording. It is likely that this was influenced by his continued study of vibrato production as well as his striving for a rich, dark, and more open sound. The combination of these components yields a slower vibrato, which is evident in the performance practice of today.

An analysis of Martin Ruderman's recording is unique to this study, as it appears that he received no formal French-influenced training. Of course, it is important to take into account his access to recordings as a studio musician and the likelihood that he encountered Frenchinfluenced recordings due to the various similarities between his 1947-8 recording and Moyse's

113 Toff, The Flute Book, 102-104.

114 Powell, The Flute, 220. 
1928 recording. Jean-Pierre Rampal illustrates the influence of imitation through his vast recording output. Not only did he admit that he had no desire to move away from the French style, but he also fully intended to use his career to further awareness of the flute and its repertoire. His vibrato style generally includes a slower frequency and less constant usage than that of Moyse, indicating a distinct move toward this slower and more methodical vibrato usage by the 1950s. However, William Kincaid demonstrates the major confluence of the French Flute School vibrato usage and the pioneering of a slower vibrato, owing to his intent to develop a pedagogy for vibrato in the true spirit of the curiosity which Moyse associated with flutists of the United States.

Comparing all of the recordings in this study reveals the emergence of the French Flute School as the primary driving force behind the utilization of faster frequencies of vibrato in early flute recording and the ultimate move toward a slower vibrato by the 1950s. Georges Barrère's move to the United States coincided with Marcel Moyse's time studying at the Paris Conservatoire, and their recording output (Barrère's focusing primarily on ensemble playing) followed a similar trajectory during the 78 -rpm era. ${ }^{115}$ This points toward the convergence of the French School and the recording industry to promote the flute as a serious instrument in both solo and ensemble settings. Thus, imitation was a factor in the move toward a more universal vibrato as a result of the new availability of recordings by such masterful players.

Ultimately, the combination of the French Flute School along with recording needs influenced the early output of recordings, but the pool of artists who continued to raise awareness of the flute through recordings was dominated largely by French or French-taught recording artists. Thus, the teachers and recordings yielded the spread of a more consistent style of vibrato

\footnotetext{
${ }^{115}$ Nelson, The Flute On Record, 57-64, and 329-344.
} 
usage which was heavily influenced through imitation of that French Flute School. Even so, artists like William Kincaid began to desire a strengthening of the pedagogy surrounding vibrato, and overtime - as evidenced through this study summarized in Figures 10 and 11 - the vibrato began to slow in frequency and result in the existing more universal practice of today. In summary, while no distinct conclusions regarding the effect of the recording needs can be drawn from this case study alone, it is quite obvious that the French Flute School was already making use of vibrato - prior to the initial 1928 recording included in this study — and the recording industry facilitated this practice allowing it to not only spread via imitation but eventually develop into the vibrato performance practice and pedagogy known more universally today. This research, although small in initial scope of study, has the potential to lend itself toward a significant understanding of not only flute vibrato practice but why this practice exists in flute pedagogy today. The hope is that this study will lay the framework for further exploration of a larger body of flute repertoire and recording artists of the twentieth century. 


\section{$\underline{\text { Appendix }}$}

Claude Debussy, Syrinx, Measures 1-2

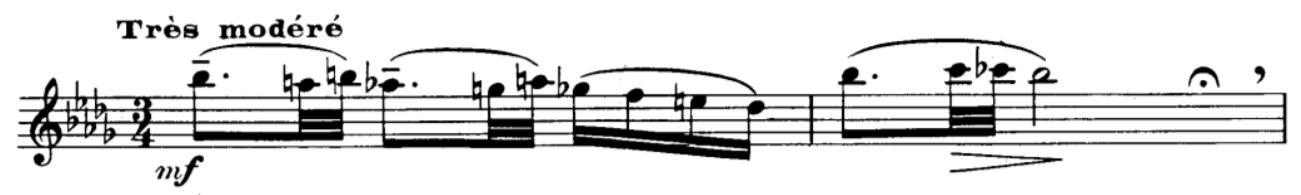

Claude Debussy, Syrinx, Measures 6-8

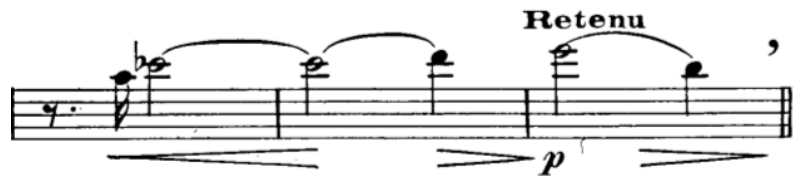

Claude Debussy, Syrinx, Measures 9-12
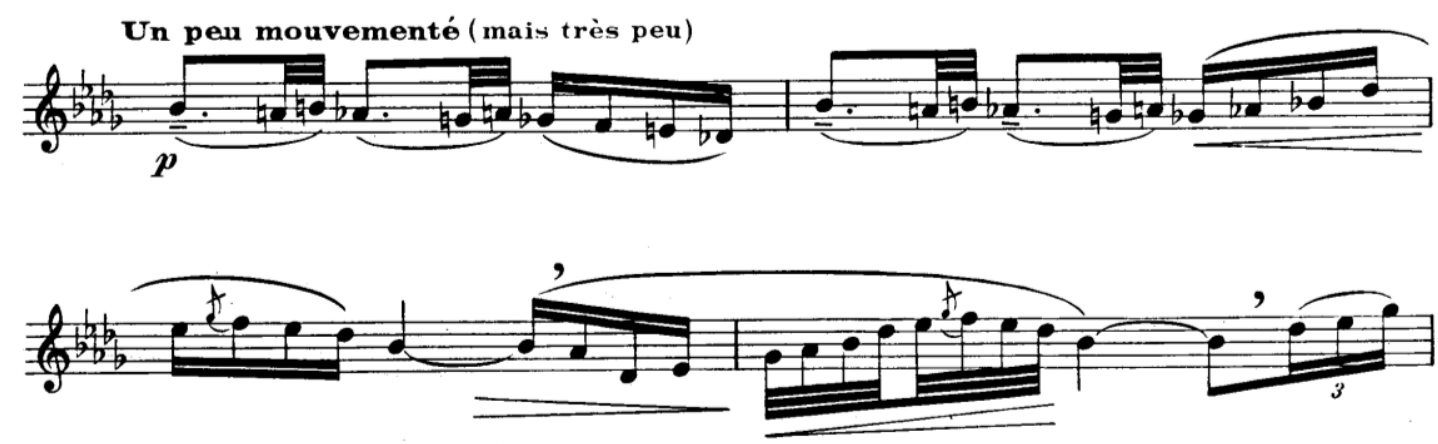
Claude Debussy, Syrinx, Measures 14-17
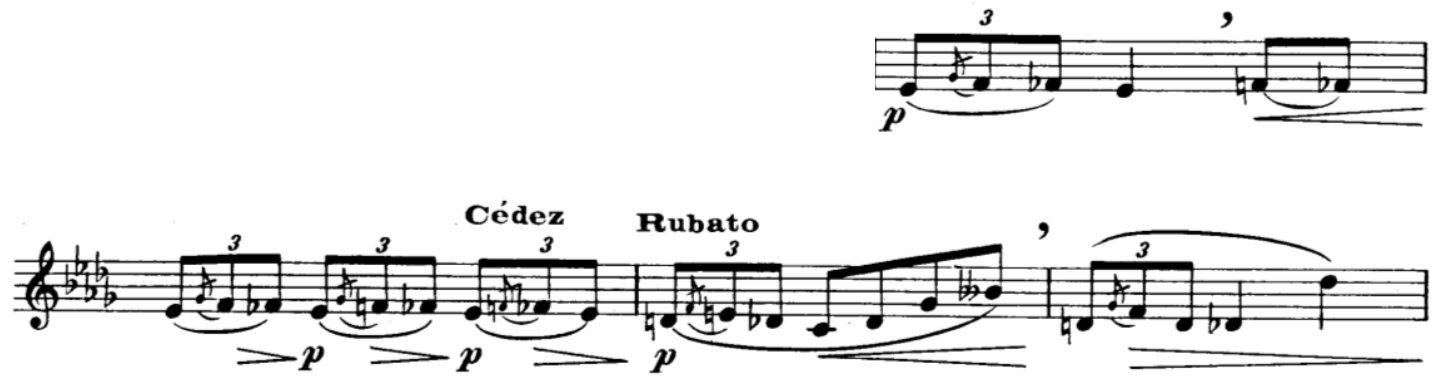

Claude Debussy, Syrinx, Measures 25-28
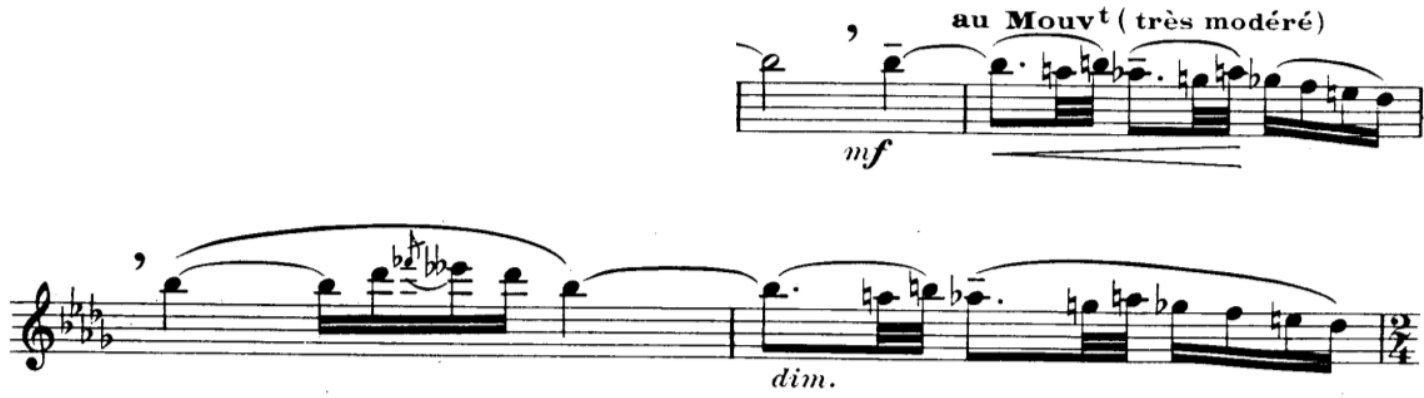

Claude Debussy, Syrinx, Measures 31-35

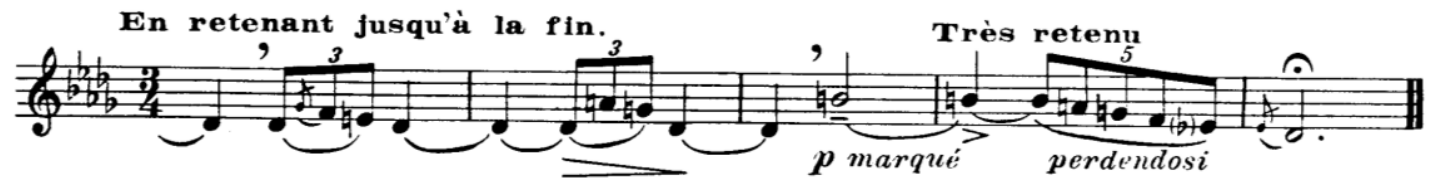




\section{Bibliography}

Barrère, Georges. "Expression Unconfined." The Musical Quarterly 30, no. 2 (April 1944): 192197. http://www.jstor.org/stable/739452 (accessed January 22, 2017).

Bigio, Robert. "Christopher Steward's Early Flute Recordings.” Robert Bigio Flute Pages. Accessed January 17, 2017. http://www.robertbigio.com/recordings.htm.

Blakeman, Edward. Taffanel: Genius of the Flute. New York: Oxford University Press, 2005.

Chapman, Frederick B. Flute Technique. New York: Oxford University Press, 1973.

Debost, Michel. The Simple Flute: An A to Z Guide. New York: Oxford University Press, 2002.

De Lorenzo, Leonardo. My Complete Story of the Flute: the Instrument, the Performer, the Music. Lubbock, TX: Texas Tech University Press, 1992.

Dorgeuille, Claude, and Edward Blakeman. The French Flute School: 1860-1950. London: Bingham, 1986.

Fair, Demetra Baferos. "Flutists' family tree: In search of the American flute school." D.M.A. diss., The Ohio State University, 2003. In ProQuest Dissertations and Theses, https://search.proquest.com/docview/305318023 ?accountid=2837 (accessed January 23, 2017).

Feldman, Martha. The Castrato: Reflections on Natures and Kinds. Berkeley: University of California Press, 2015.

Finson, Jon W. "Performing Practice in the Late Nineteenth Century, with Special Reference to the Music of Brahms." The Musical Quarterly 70, no. 4 (1984): 457-75. http://www.jstor.org/stable/741892 (accessed January 23, 2017).

Gärtner, Jochen. The Vibrato, with Particular Consideration Given to the Situation of the Flutist: Historical Development, New Physiological Discoveries, and Presentation of an Integrated Method of Instruction. Regensburg: G. Bosse, 1981.

Horning, Susan Schmidt. Chasing Sound: Technology, Culture, and the Art of Studio Recording from Edison to the LP. Baltimore: John Hopkins University Press, 2013.

Katz, Mark. Capturing Sound: How Technology Has Changed Music. Berkeley: University of California Press, 2010.

Kincaid, William. Music for the flute. New York: Columbia. LP. 1950. 
Kincaid, William, and Claire C. J. Polin. The Advanced Flutist: A Guide to Multiple Tonguing, Vibrato and Sensitive Fingering. Bryn Mawr: Elkan-Vogel, 1975.

Krell, John C. Kincaidiana: A Flute Player's Notebook. Santa Clarita, CA: The National Flute Association, Inc., 1997.

Lawrence, Eleanor. "Interview with Paige Brook." National Flute Association Newsletter 3, no. 1 (1977): 3.

Library of Congress Music Division concert. "Philadelphia Woodwind Quintet.” William Kincaid, flute. Syrinx by Claude Debussy. Live recording. February 13, 1953.

Library of Congress Music Division concert. "Trio Moyse." Marcel Moyse, flute. Syrinx by Claude Debussy. Live recording. March 10, 1950. Sound recording. 1967.

McCutchan, Ann. Marcel Moyse: Voice of the Flute. Portland, OR: Amadeus Press, 1994.

“Marcel Moyse Profiled.” Woodwind Magazine 2, no. 5, 1950.

Moyse, Marcel, Georges Truc, Claude Debussy, and Claude Paul Taffanel. Syrinx. London: Columbia. 78 rpm. 1928.

Moyse, Marcel, Blanche Honegger Moyse, Carol Wincenc, Julia Bogorad. Flute Seminars, 1975: Tape \#1: A Conversation with Blanche Moyse. DVD. West Brattleboro, Vt.: Moyse Enterprises, 1989.

Moyse, Marcel, Blanche Honegger Moyse, Carol Wincenc, Julia Bogorad. Flute Seminars, 1975: Tape \#7: 24 Small Melodic Studies No. 9, flutist Sara Tutland; Syrinx, Debussy; flutist, Marie Herseth. DVD. West Brattleboro, Vt.: Moyse Enterprises, 1989.

National Flute Association (U.S.). The Flutist's Handbook: A Pedagogy Anthology. Santa Clarita, CA: The National Flute Association, Inc., 1998.

Nelson, Susan. The Flute on Record: The 78 Rpm Era: A Discography. Lanham, MD: Scarecrow Press, 2006.

Philip, Robert. Early Recordings and Musical Style: Changing Tastes in Instrumental Performance, 1900-1950. New York: Cambridge University Press, 1992.

Philip, Robert. Performing Music in the Age of Recording. New Haven: Yale University Press, 2004.

Powell, Ardal. The Flute. New Haven: Yale University Press, 2002.

Praetorius, Michael. Syntagma Musicum Vol. III. Wolfenbüttel, 1619; Reprint Kassel, Bärenreiter, 1958. 
Pritchard, Jan. "Remembering Roger S. Stevens." The Flute Network. Accessed March 24, 2017. http://www.flutenet.com/stevens.htm.

Rampal, Jean-Pierre. Le Premier Virtuose Moderne. France: Association Française de la Flûte, CD. 2002. Syrinx, by Claude Debussy. Jean-Pierre Rampal. 1949.

Ruderman, Martin. Syrinx for flute solo. Hollywood, Calif: ALCO Records. LP. 1947-8.

Spohr, Louis. Violinschule. Haslinger: Vienna, 1832.

Taylor, Timothy D., Mark Katz, and Tony Grajeda, eds. Music, Sound, and Technology in America: A Documentary History of Early Phonograph, Cinema, and Radio. Durham: Duke University Press, 2012.

Toff, Nancy. Monarch of the Flute: The Life of Georges Barrere. Oxford: Oxford University Press, 2005.

Toff, Nancy. The Flute Book: A Complete Guide for Students and Performers. New York: Oxford University Press, 1996.

Tromlitz, Johann George. The Virtuoso Flute-Player. Edited by Ardal Powell. Cambridge [England]: Cambridge University Press, 1991.

Verville, Timothy. "Instrumental Vibrato: An Annotated Bibliography of Historical Writings before 1940.” D.M.A. diss., Arizona State University, 2012. In ProQuest Dissertations and Theses, https://search.proquest.com/docview/1010270372?accountid=2837 (accessed January 19, 2017).

Waddell, Rachel Lynn. "Marcel Moyse between Two Centuries: Examining Early TwentiethCentury French Flute Performance Practice through Recordings.” D.M.A. diss., The University of Nebraska - Lincoln, 2002. In ProQuest Dissertations and Theses, https://search.proquest.com/docview/305502505 ? accountid=2837 (accessed January 19, 2017).

Weiner, Neal, Michel Moyse, and Claude Moyse. Marcel Moyse: Grand Old Man of the Flute. DVD. West Brattleboro, Vt.: Moyse Enterprises, 2000.

Wye, Trevor. Marcel Moyse: An Extraordinary Man. Cedar Falls, Iowa: Winzer Press, 1993. 